\title{
Design of a Teleoperated Aquatic Vehicle for the Gauging of Water Bodies
}

\author{
C.E. Díaz-Gutiérrez ${ }^{* 1}$, M.P. Garduño-Gaffare ${ }^{2}$, J.A. Segovia-De los Ríos ${ }^{3}$, J.S. Benítez-Read ${ }^{4}$ \\ ${ }^{1,2}$ Instituto Tecnológico de Toluca \\ Av. Tecnológico S/N, C.P. 52140 \\ Toluca, Mexico \\ *carlos_eduardo_dg@yahoo.com.mx \\ $1,3,4$ Instituto Nacional de Investigaciones Nucleares \\ Carretera México-Toluca S/N, C.P. 52750 \\ La Marquesa, Ocoyoacac \\ Estado de México, México
}

\begin{abstract}
The sampling and flow measurement of rivers is a very complex task, not only because of the amount of equipment to be carried and the parameters to be measured, but also because of the health risk involved for people who have to perform this activity frequently. For this reason, a flow measurement system named as SA-1 (Gauging System SA-1) has been designed, and built and, proposed as an innovative alternative, which is a teleoperated watercraft. This article describes this system and its mathematical models.
\end{abstract}

Keywords: water-flow-measurement, watercraft-design, teleoperated-system, unmanned-surface-vehicle, mathematical models.

\section{RESUMEN}

El muestreo y aforado de ríos es una tarea compleja, no solo por la cantidad de equipo que hay que transportar y los parámetros que hay que medir, sino por el alto riesgo que existe para las personas que tienen que realizar esta tarea de manera frecuente. Por esta razón se propuso el diseño y la construcción de un novedoso sistema automático de medición de caudales denominado SA-1, el cual es una plataforma acuática teleoperada. Este artículo describe este sistema y sus modelos matemáticos.

\section{Introduction}

Through flow measurement in water bodies, it is possible to determine its availability and pollution. Currently, the appraisal of water bodies in Mexico is done using the flowmeter sensors and, in many cases, the staff responsible of this activity must get into the water body and write on paper the readings obtained by the sensor. The risk posed to these workers is high, due to the possibility of having an accident by the presence of strong currents or getting a disease by the presence of contaminants in the water body.

While there is highly sophisticated equipment worldwide to perform the task of flow measurement such as ultrasonic sensors, for example, their high cost make them practically inaccessible [1, 2]. Gonzalez et al. [3], developed the "system for the automatization of volume measurement using windlass". This system solves the problem partly; however, the worker enters in contact with the water body (for more information about flow measurement systems see the article: "Medición de Caudales Mediante la implementación de un vehículo acuático teleoperado" [4]). Hence, a new alternative for water flow measurement, which has been termed as "Gauging System 1" (SA-1) is proposed.

With the creation of SA-1 the following benefits are sought: safeguarding the physical integrity of people, safeguarding the health of people, simplifying the sampling process, reducing costs and diminishing time for this activity. 
To carry out theoretical studies involving a mobile robot, a complete mathematical model must be developed, which can be used to evidence, through simulations, the influence of changes on the robot's characteristics, thus making the planning of control strategies to cope with any task possible. The use of computer simulation in the design of control systems involving aquatic robots requires the development of kinematic and dynamic models that incorporate the main behavior characteristics. In this manner, modifications in the control scheme, aimed to obtain the best possible solution, are allowed before the physical implementation. Likewise, different solutions offering similar performances can be further evaluated in terms of the simplicity of their implementations [5].

Mobile robots can be built based on different platforms, which differ in the kind of traction system used. The kinematic models of the most common platforms are based on differential steering. Similarly, there exist numerous dynamic models that describe the behavior of an aquatic system. However, the complexity of these models is a function of the number of hydrodynamics coefficients that must be computed experimentally through tow-tank or computational fluid dynamics analysis. As more hydrodynamic coefficients are determined, the accuracy of the model developed is closer [6] to real conditions, and vice versa, as less hydrodynamics coefficients are calculated, the model is simpler, and less close to the real system conditions.

Instead of determining these coefficients from physical principles, which can be a complicated task, some empirical equations can be used to obtain their values and still get a good approximation of the characteristics of the robot floats, such as those proposed by VanZweeten [7] for the modeling of the autonomous surface vehicle Delfim. Once the values of the hydrodynamic coefficients have been obtained, the Nomoto model is used to describe "the course of keeping yaw dynamics" under the assumptions that small rudder angles are involved and the forward speed is considerated constant [8,9]. The Nomoto model is very popular due to its simplicity and relative accuracy.
The aim of this work is, in first instance, to design a system that performs the flow measurement of water bodies, followed by the development of the kinematic and dynamic models using unexplored criteria such as the pitch of the thrusters for the kinematics and the use of empirical equations, employed in large ships, to calculate the hydrodynamic coefficients required in the dynamic model. To validate the model, the response to the step signal is compared with respect to other models having similar characteristics to those of the SA-1.

The robot thrusters were also modeled. Once the model was obtained, a PWM (pulse width modulation) function was found. This function, obtained experimentally, was used to map a PWM value to an output voltage for the thrusters, thus obtaining a corresponding angular speed.

The driving of the robot was made through a Microsoft Sidewinder wheel, which will be named hereafter as the rudder.

\section{Considerations to design the gauging system SA-1}

The SA-1 is a small teleoperated watercraft physically inspired by some others systems, such as the proposed by Massimo Caccia (SESAMO platform) [10], the platform DELFIM developed by J. Alves from the Institute for Systems and Robotics in Lisbon, Portugal [11], the NIMS-AQ platform developed by Michael J. Stealey from UCLA [12] and ROAZ, and a surface vehicle developed by Hugo Ferreira [13], among others.

Figure 1 shows the SA-1, which was designed to carry the various components required to realize the flow measurement in water bodies. As it can be seen, this watercraft is composed of three main parts: two side floats and a casing that houses the central computer system, power electronics, measuring instruments, and power source.

\subsection{Mechanical description of the measurement system SA-1}

The SA-1 has a measurement system responsible for taking readings in different bodies of water, 
using a flowmeter sensor and the area-velocity technique described above. This system is composed of a) a transmission system, b) the device containing the flowmeter sensor and c) an anchor whose function is to hold and stabilize the aquatic platform at the time of the readings. All these elements together compose the measurement system. Figure 2 illustrates this concept.

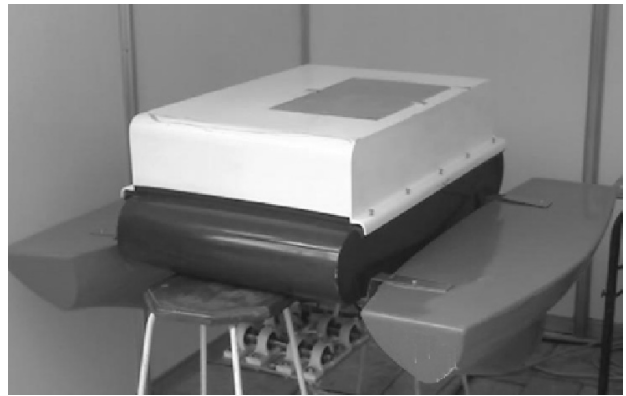

Figure 1. Gauging system SA-1

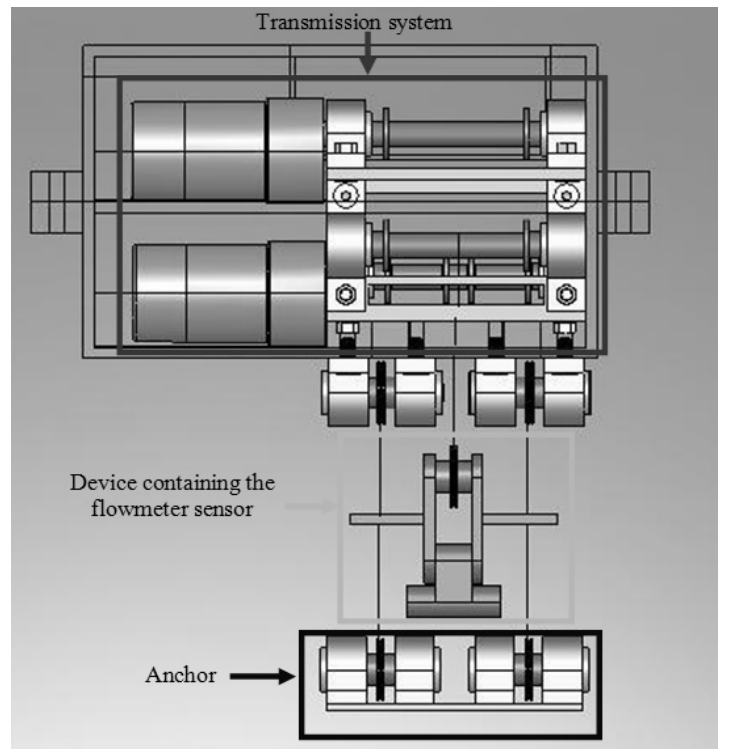

Figure 2. Mechanical components of the measurement system SA-1.

The transmission system has two DC motors. One motor is in charge of the ascending and descending motion of the device containing the flowmeter sensor, and the second one has the task of moving up and down the anchor as required.
Each motor has an electrical power output of 62.16 W $(1 / 12 \mathrm{hp})$, a mass of $5 \mathrm{~kg}(2.3 \mathrm{lb})$ and is provided with a gear box to obtain $115 \mathrm{rpm}$ and augment the torque in the output shaft to get a torque of $4.8 \mathrm{~N}-\mathrm{m}$ (43 lb-in). These motors are connected to a set of shafts whose purpose is to transmit motion to other parts of the systems that require it, such as the anchor and the device containing the flowmeter sensor. The measurement system has also pulleys and steel cable.

\subsection{Hardware of the SA-1 system}

Figure 3 shows the control hardware of the SA-1.

A description of the most important elements is necessary for the development of this paper:

a) PCM-9375. The PCM-9375 is a low-power and high-performance single-board computer (SBC) [14]. Its processor provides simplified programming capability and a friendly user environment. This computer performs communication operations between the SA-1 and the user terminal, and the interpretation of data coming from the flowmeter sensor readings or any other sensor installed in the aquatic platform. There exist other high cost computers with capabilities to control directly the hardware components. In order to achieve a lowcost system, it was decided to use a hybrid structure using a PCM-9375 interfaced to a microcontroller single-board computer Servopod from Newmicros. The program running on the PCM-9375 was developed in Java and it is in charge of some control operations and also sends the signals, transmitted by the user through the land computer to the microcontroller.

b) Microcontroller Servopod. This type of controller is widely used in robotics and industrial applications. Its high performance characteristics make it useful for controlling the motors and thrusters of the SA-1. The servopod can be programmed in several languages such as Forth, Small C, Static C and assembler or in the resident language of the microcontroller: Isomax. It is used to control the thrusters, motors and sensors of the SA-1.

c) Power circuit or speed controller. The speed stages of the motors and thrusters are controlled 


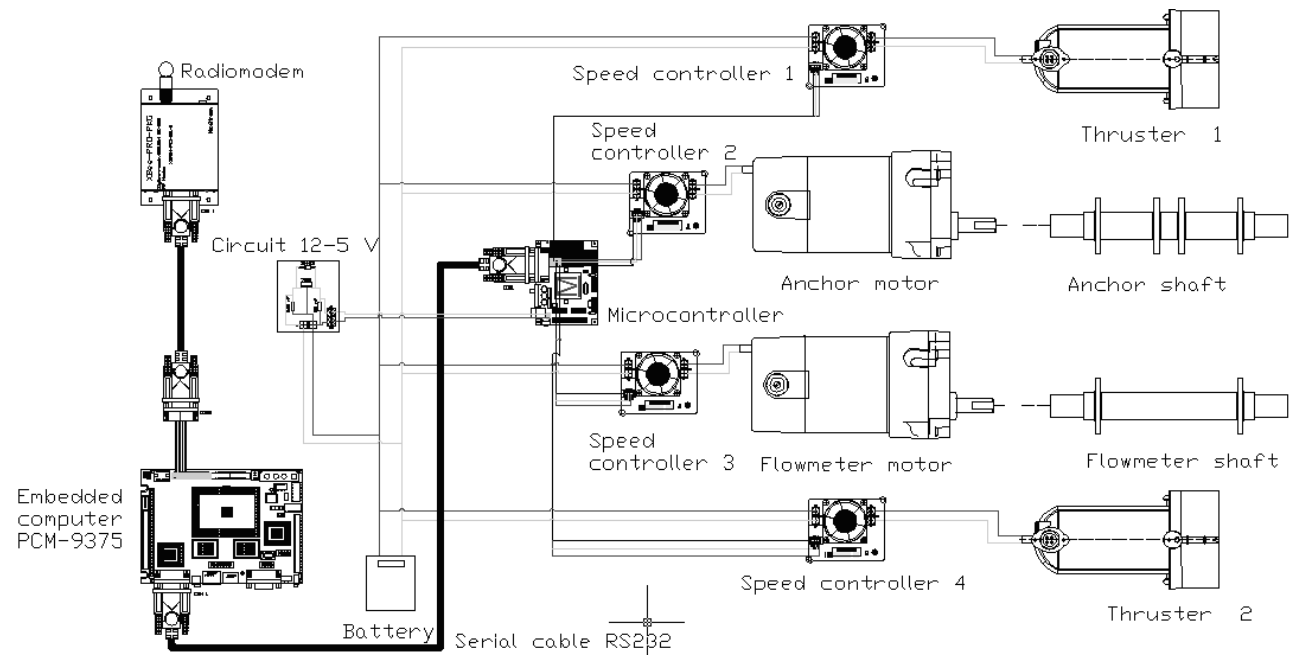

Figure 3. Control hardware of the SA-1.

through the use of four speed controllers. The speed controllers are in charge of increasing or decreasing the angular speed of the thrusters and the motors, according to the PWMs values calculated by the program running in the Servopod, for each motor and thruster to produce the movements requested by the user. These amplifiers operate in such a way that they need an input signal similar to that used to control a model servomotor.

d) Battery. Its function is to provide electric power to the hardware elements. A battery with a capacity of at least $27.46 \mathrm{Ah}$ is required. This refers to a maximal consumption. However, given that neither the motors nor the thrusters are working at $100 \%$ at the same time, the consumption is considerably reduced. In fact, the chosen power supply system consists of a $12 \mathrm{~V}$ battery with capacity of 20 Ah connect in series with another battery of $6 \mathrm{~V}$.

e) Wireless link. The communication between the SA-1 and the user terminal is done using a couple of radio modems. A radio modem is connected to an USB port of the terminal of operation and the other is connected to an USB port of the PCM9375 on board of the watercraft.
The SA-1 has a weight of $912.33 \mathrm{~N}$. Its dimensions are: length $1 \mathrm{~m}$, width $1 \mathrm{~m}$, height $0.60 \mathrm{~m}$ (from the base of the floats to upper housing).

With the description of all elements of the SA-1, it is possible to develop the kinematic and dynamic models. In the analysis, the anchor is not considered.

\section{Kinematic model}

\subsection{Study of the Propulsion System}

Due to the importance of pitch in the development of this work, it is necessary to determine its value through of the following procedure, this is an aspect no treated yet by other researchers.

For the SA-1 kinematic modeling, it is necessary to consider that this aquatic platform presents a differential locomotion, i.e., analogous to differential overland robots; however, in this particular case, instead of considering the radius of the wheels, the pitch of the propellers of the thrusters is considered.

The pitch of a thruster is the displacement that the propellers can achieve in one revolution [15]. Figure 4 illustrates this concept. 


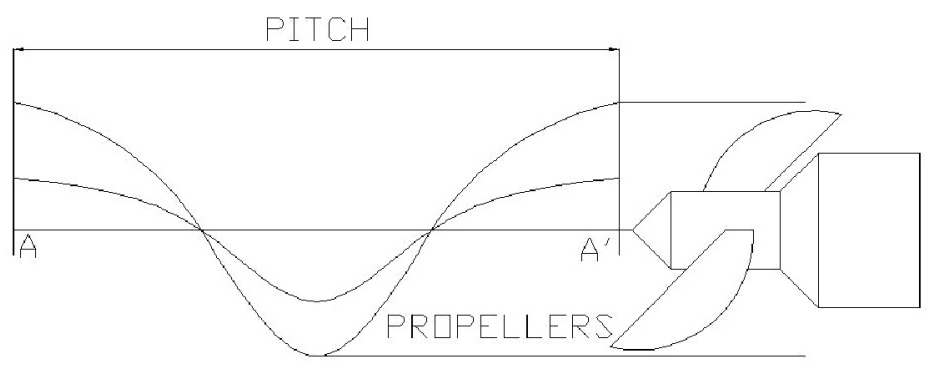

Figure 4. Pitch of the thrusters' propellers.

In consequence, it is necessary to establish the pitch of the propellers for this class of thrusters. In general terms, the pitch of a thruster is [16]

$$
\mathrm{P}=\frac{2 \pi r}{\tan \theta}
$$

where $P$ is the pitch of the thrusters' propellers, $\theta$ is the angle shown in Figure 5, and $r$ is the radius of the propellers' blade.

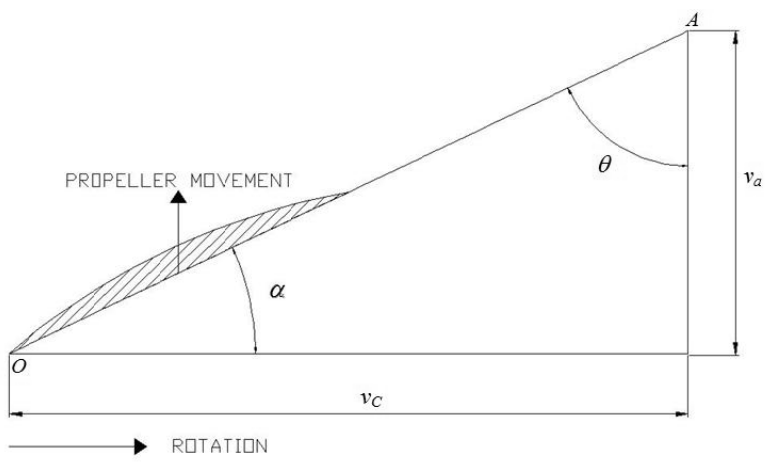

Figure 5. Angle $\theta$ and its relationship with the advance speed $v_{a} . v_{c}$ is the speed of a particle situated on the face of the propeller.

Likewise, the pitch of a propeller [17] can by calculated with the expression:

$$
\mathrm{P}=2 \pi c
$$

being $c$ the parameter to calculate. Equaling Equations (1) and (2) and solving for $c$ :

$$
c=\frac{r}{\tan \theta}
$$

Hence, the parametric equations of the propeller are

$$
\begin{aligned}
& x=r \cos t \\
& y=r \operatorname{sen} t \\
& z=\frac{r}{\tan \theta} t
\end{aligned}
$$

$t$ is the time required to complete a propeller revolution. For $r=0.038 m$ and $\theta=67.28^{\circ}$,

$$
\begin{aligned}
& x=38 \cos t \\
& y=38 \operatorname{sen} t \\
& z=\frac{50}{\pi} t
\end{aligned}
$$

The results obtained using the expressions of Equation (5), with $P=0.10 \mathrm{~m}$, are shown in Section 8.

\subsection{Propellers Efficiency}

It is necessary to compute the theoretical efficiency $\eta_{0}$ of the propellers. This efficiency will be useful in some models, such as the thruster model. Therefore, the advanced coefficient $[15,16]$ is considered, which is given by the following expression:

$$
J=\frac{v_{a}}{\omega D}
$$

where $v_{a}$ is the advanced speed of the propellers, $\omega$ is the angular speed, and $D$ is the diameter of the propellers. 
It is possible to determine $v_{a}$ using the following equation:

$$
p=E v_{a}
$$

where $p$ is the power, and, $E$ is the thrust

It is feasible to establish the real power and thrust of the thrusters, according with the graph shown in Figure 6 (Courtesy of the thrusters manufacturer [18]).

A voltage $V$ of $18 \mathrm{~V}$, produces a current $i$ of $3.32 \mathrm{~A}$ and a thrust of $1.43 \mathrm{~kg}_{f}$ equivalent to $14.02 \mathrm{~N}$. With this information, the power may be recalculated with the expression:

$$
p=V i
$$

The last equation considered the power losses, according to shown in figure 6 . Substituting this value of $p$ in Equation (7), the value of $v_{a}$ obtained is $4.262 \mathrm{~m} / \mathrm{s}$.

Considering the value of $v_{a}$, an angular speed of $471.24 \mathrm{rad} / \mathrm{s}$ (75 rps) and a propeller diameter of $0.076 \mathrm{~m}$, the advanced coefficient is, according to Equation (6), $J=0.75$.

Similarly, the thrust coefficient can be determined using the equation

$$
K_{T}=\frac{E}{\rho \omega^{2} D^{4}}
$$

where $\rho=1000 \mathrm{~kg} / \mathrm{m}^{3}$ is the water density. Hence, $K_{T}=0.074$.

The torque coefficient, $K_{Q}$, can be obtained using the graph reported by Velasco et al. [15]. The parameters required are the advanced coefficient, the thrust coefficient, and the ratio between the pitch and the propeller diameter $(P / D)$, which in this case is 1.3. Using this ratio and the values of $J$ and $K_{T}$ previously obtained, the value of the torque coefficient is $K_{Q}=0.02$.

The propeller efficiency can be obtained using the following expression:

$$
\eta_{o}=\frac{K_{T}}{K_{Q}} \frac{J}{2 \pi}
$$

Substituting values in this equation, the propeller efficiency obtained is $\eta_{0}=44.16 \%$.

\subsection{Kinematic model}

The kinematic model was developed using the parameters of the SA-1 robot shown in figure 7 .

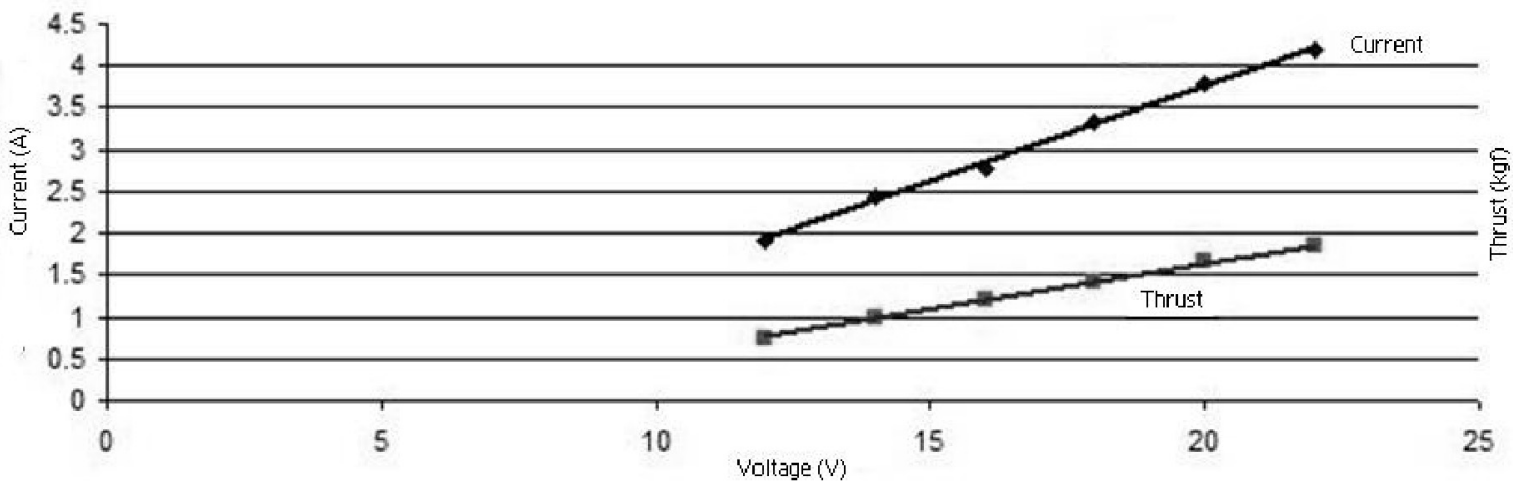

Figure 6. Current vs. voltage and thrust vs. voltage. 


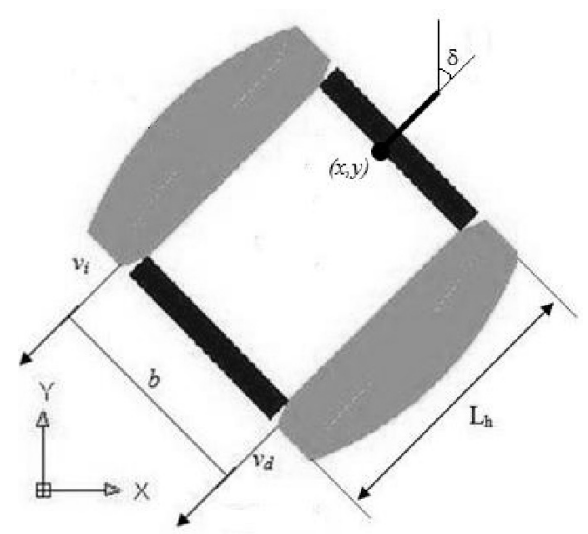

Figure 7. Scheme used to determined the kinematic model (Configuration proposed by Ollero) [19].

When it comes to the differential guided locomotion, the control variables are the angular velocities of the propellers. If $\omega_{i}$ and $\omega_{d}$ are the speed gyros of the left and right propellers, respectively, the corresponding linear speeds are $v_{i}=\omega_{i} P$ and $v_{d}=$ $\omega_{d} P$. It follows that,

$$
\begin{aligned}
& v=\frac{v_{d}+v_{i}}{2}=\frac{\left(\omega_{d}+\omega_{i}\right) P}{2} \\
& \omega=\frac{v_{d}-v_{i}}{b}=\frac{\left(\omega_{d}-\omega_{i}\right) P}{b}
\end{aligned}
$$

where $b(b=1 \mathrm{~m})$ is the distance between thrusters.

In general terms, the equations that govern a vehicle with differential guide [19-23] are

$$
\left[\begin{array}{l}
x \\
y \\
\phi
\end{array}\right]=\left[\begin{array}{l}
x_{0} \\
y_{0} \\
\phi_{0}
\end{array}\right]+\left[\begin{array}{c}
-\int_{0}^{t} \frac{r}{2} \operatorname{sen} \delta\left(\omega_{d}+\omega_{i}\right) d t \\
\int_{0}^{t} \frac{r}{2} \cos \delta\left(\omega_{d}+\omega_{i}\right) d t \\
\int_{0}^{t} \frac{r}{b}\left(\omega_{d}-\omega_{i}\right) d t
\end{array}\right]
$$

where $r$ is the radio of the wheels of a land vehicle. If $x_{0}=y_{0}=z_{0}=0$, and recalling that, $r$ is equal to the pitch $P$, for this particular case, then, Equation (13) can be written as

$$
\left[\begin{array}{l}
x \\
y \\
\phi
\end{array}\right]=\left[\begin{array}{c}
-\int_{0}^{t} \frac{P}{2} \operatorname{sen} \delta\left(\omega_{d}+\omega_{i}\right) d t \\
\int_{0}^{t} \frac{P}{2} \cos \delta\left(\omega_{d}+\omega_{i}\right) d t \\
\int_{0}^{t} \frac{P}{b}\left(\omega_{d}-\omega_{i}\right) d t
\end{array}\right]
$$

This is the kinematic model proposed for the SA-1 robot in function of pitch. The simulation results obtained with this model are shown in Section 8.

\section{Dynamic model of the SA-1 Robot}

\subsection{Reference systems}

The SA-1 can be considered as a rigid body with six independent coordinates (Figure 8), For this system, a reference system attached to the robot $x, y, z$, and other coordinate system attached to the earth $x_{0}, y_{0}$, $z_{0}$, are considered. Given the kinematic model of the SA-1, the following movements are possible: rotations around the $x, y$, and $z$ axes and movements along the $x_{0}, y_{0}$ and $z_{0}$ axes In general, the most important movements of the SA-1 occur in the

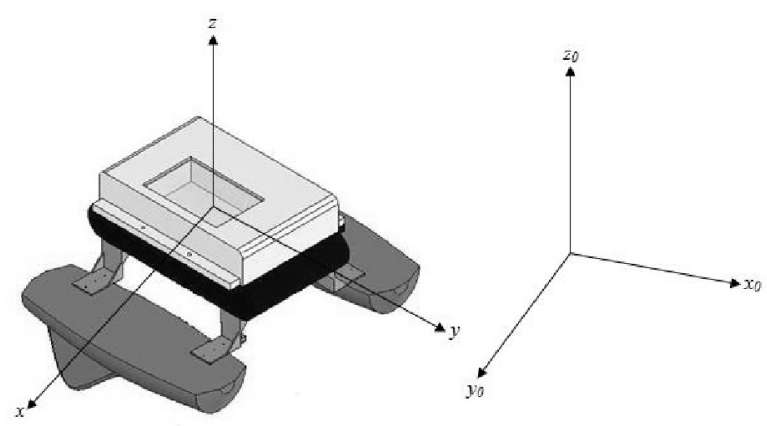

Figure 8. Definition of the SA-1 coordinate system (configuration proposed by Ayza [24]). 
horizontal plane $x_{0}, y_{0}$. Hence, the movements of rotations in the $x$ and $y$ axes, and displacements in the $z$ axis are assumed to be negligible [24].

Thus, the movement of the SA-1 can be defined in terms of the following variables (Figure 9):

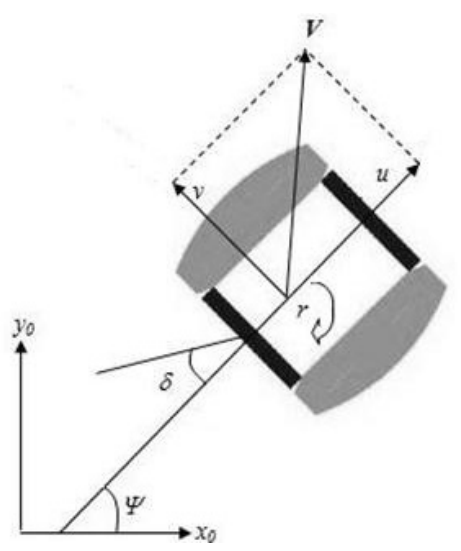

Figure 9. Variables used in the development of the dynamic model.

$x_{0}, y_{0}$ give the SA-1 position with respect to the earth fixed reference; $\delta$ is the gyro angle of the SA-1 or rudder angle (This concept is explained later); $\psi$ is the yaw angle; $V$ is the absolute speed of the SA-1, where $u$ and $v$ are its $x$-axis and $y$-axis components, respectively, and $r$ is the yaw speed (note that $\psi^{\prime}=r$ ).

\subsection{Dynamic equations}

The purpose of this section is to determine the physical equations of the model and thus establish the hydrodynamics coefficients required in the dynamic model.

The starting point is the set of equations, based on physical principles, corresponding to the surge, sway, and yaw motions [25].

Surge:

$$
X=m\left(u^{\prime}-v r-x_{G} r^{2}\right)
$$

Sway:

$$
Y=m\left(v^{\prime}-u r+x_{G} r^{\prime}\right)
$$

Yaw:

$$
N=I_{z} r^{\prime}+m x_{G}\left(u r+v^{\prime}\right)
$$

where $m$ is the mass of the SA-1, $x_{G}$ is the position of the $x$ coordinate of the gravity center, $r$ is yaw speed, $r^{\prime}$ is the yaw angular acceleration, $v^{\prime}$ is the acceleration component along the $y$ axis, $I_{z}$ is the inertial moment referred to the $z$ axis, $X$ is the external force exerted on the robot in the $x$ axis direction, $Y$ is the external force exerted on the robot in the $y$ axis direction, and $N$ is the external moment exerted refereed to the $z$ axis.

Assuming that the small yaw speed $r$ and angle $\delta$ are small, then it can be also considered that the speed $u$ and thrust $E$ of the robot are constant [25]. Therefore, Equation (15) can be uncoupled from the other two (16 and 17). Hence, for small perturbations around the nominal values $u, v$ and $r$, Equations (15), (16), (17) can be written as

Surge:

$$
X=m u^{\prime}
$$

Sway:

$$
Y=m\left(v^{\prime}-u r^{\prime}+x_{G} r^{\prime}\right)
$$

Yaw:

$$
N=I_{z} r^{\prime}+m x_{G}\left(u r+v^{\prime}\right)
$$

The first equation (18) relates the thrust with the boat's speed, and although this relationship is essentially nonlinear, in the study of government of the boat by linear models expressions (19) and (20) the govern equations are considered [25].

Linearizing the functions $Y$ and $\mathrm{N}$, given in Equations (19) and (20), about the equilibrium state $v=r=\delta=$ 0 , the following equations are obtained $[9,25]$ :

$$
\begin{aligned}
& Y=Y_{v} v+Y_{v^{\prime}} v^{\prime}+Y_{r^{\prime}} r^{\prime}+Y_{\delta} \delta \\
& N=N_{v} v+N_{v^{\prime}} v^{\prime}+N_{r^{\prime}} r^{\prime}+N_{\delta} \delta
\end{aligned}
$$

Replacing (21) and (22) in the govern equations (19) and (20), and ordering, it results [24, 25, 26]: 


$$
\left[\begin{array}{cc}
m-Y_{v^{\prime}} & m x_{G}-Y_{r^{\prime}} \\
m x_{G}-N_{v^{\prime}} & I_{z z}-N_{r^{\prime}}
\end{array}\right]\left[\begin{array}{l}
v^{\prime} \\
r^{\prime}
\end{array}\right]=\left[\begin{array}{cc}
Y_{v} & Y_{r}-m u \\
N_{v} & N_{r}-m x_{G} u
\end{array}\right]\left[\begin{array}{l}
v \\
r
\end{array}\right]+\left[\begin{array}{c}
Y_{\delta} \\
N_{\delta}
\end{array}\right] \delta
$$

or

$$
M\left(v^{\prime}, r^{\prime}\right)=N(v, r)+\tau\left(Y_{\delta}, N_{\delta}\right)
$$

where $M$ is the inertia matrix of the system, defined as

$$
M=\left[\begin{array}{cc}
m-Y_{v^{\prime}} & m x_{G}-Y_{r^{\prime}} \\
m x_{G}-N_{v^{\prime}} & I_{z z}-N_{r^{\prime}}
\end{array}\right]
$$

$N$ is the hydrodynamic coefficient matrix, defined as

$$
N=\left[\begin{array}{cc}
Y_{v} & Y_{r}-m u \\
N_{v} & N_{r}-m x_{G} u
\end{array}\right]
$$

and $\tau$ is the coefficient vector related to the thrust and moment exerted by the thrusters, defined as

$$
\tau=\left[\begin{array}{c}
Y_{\delta} \\
N_{\delta}
\end{array}\right]
$$

The coefficient $Y_{V}$ is obtained using the following expression [7, 15, 24, 27]:

$$
Y_{v}=C_{F} \operatorname{sen}\left(\mu_{a}\right) q A_{L}
$$

Where $C_{F}$ is a negative constant that depends on the structure of the floats, $\mu_{a}$ is the angle of wind direction, $A_{L}$ is the area on the water line of the projection of the floats in the plane $x-y$, and $q$ is the wind press on the floats. This parameter is given by [24]:

$$
q=\frac{1}{2} \rho_{a} V_{\text {wind }}
$$

Where $\rho_{a}$ is the wind density, and $V_{\text {wind }}$ is the speed of the wind.
For this particular case, $\rho_{a}=1.2 \mathrm{~kg} / \mathrm{m}^{3}$ and $V_{\text {wind }}=1$ $\mathrm{m} / \mathrm{s}$.

The expressions to determine the coefficients $Y_{v^{\prime}}, Y_{r}$, and $Y_{r^{\prime}}$ are $[15,24,26,27]$ :

$$
Y_{v^{\prime}}=-\pi\left(\frac{T}{L_{p p}}\right)^{2}\left(1+0.16 C_{B} B\left(\frac{B}{T}\right)-5.1\left(\frac{B}{L_{p p}}\right)^{2}\right)\left(\frac{\rho}{2} L^{2} T\right)
$$

$$
Y_{r}=-\pi\left(\frac{T}{L_{p p}}\right)^{2}\left(-0.5+2.2\left(\frac{B}{L_{p p}}\right)-0.08\left(\frac{B}{T}\right)\right)\left(\frac{\rho}{2} L^{3} T\right)
$$

$$
Y_{r^{\prime}}=-\pi\left(\frac{T}{L_{p p}}\right)^{2}\left(\frac{0.67 B}{L_{p p}}-0.0033\left(\frac{B}{T}\right)^{2}\right)\left(\frac{\rho}{2} L^{3} T\right)
$$

Where $T$, is the draft of the floats, $L_{p p}$ is the length between the perpendiculars of the floats, $B$ is the greatest width of the floats, $L$ is the length of the float and $C_{B}$ is the block coefficient.

$$
C_{B}=\frac{V}{L_{W L} B T}
$$

Then

$$
V=B L T
$$

is the displaced volume for the SA-1, and

$$
L_{W L}=L_{T H}+\left(\frac{L_{B H}-L_{T H}}{T_{h}+d_{W L T}}\right) d_{W L T}
$$

is the water line. $d_{W L T}$ is the water line along of the floats, and $L_{B H}$ and $L_{T H}$ are the lengths of the float at the top and bottom, respectively. 
The coefficient $N_{v}$ (moment produced by the wind) can be computed using [7, 15, 24, 26]:

$$
N_{v}=C_{M} \operatorname{sen}\left(\mu_{a}\right) q A_{L} L
$$

Where $C_{M}$ is a negative constant that depends on the floats' structure.

The expressions for the rest of the hydrodynamic coefficients $\left(N_{v}, N_{r}\right.$, and $\left.N_{r}\right)$, are $[7,25]$

$$
N_{v^{\prime}}=-\pi\left(\frac{T}{L_{p p}}\right)^{2}\left(\frac{1.1 B}{L_{p p}}-\frac{0.041 B}{T}\right)\left(\frac{\rho}{2} L^{3} T\right)
$$

$N_{r}=-\pi\left(\frac{T}{L_{p p}}\right)^{2}\left(0.25+0.039\left(\frac{B}{T}\right)-0.56\left(\frac{B}{L_{p p}}\right)\right)\left(\frac{\rho}{2} L^{4} T\right)$

$$
N_{r^{\prime}}=-\pi\left(\frac{T}{L_{p p}}\right)^{2}\left(\frac{1}{12}+0.017 C_{B}\left(\frac{B}{T}\right)-0.33\left(\frac{B}{L_{p p}}\right)\right)\left(\frac{\rho}{2} L^{4} T\right)
$$

It is necessary to multiply the results obtained by two, since the SA-1 contains two floats [7]. In the last analysis each float has been considered as single hull ship in order to use these equations.

4.3 Transfer function for yaw and transversal speed

Equation (24) can be seen as [24, 25]:

$\left[\begin{array}{c}v^{\prime} \\ \psi^{\prime \prime}\end{array}\right]=\left[\begin{array}{ll}a_{11} & a_{12} \\ a_{21} & a_{22}\end{array}\right]\left[\begin{array}{c}v \\ \psi^{\prime}\end{array}\right]+\left[\begin{array}{l}b_{11} \\ b_{21}\end{array}\right] \delta$

where the matrix:

$$
\left[\begin{array}{ll}
a_{11} & a_{12} \\
a_{21} & a_{22}
\end{array}\right]
$$

results from the matrix product [26] $-M^{-1} N$, and

$$
\left[\begin{array}{l}
b_{11} \\
b_{21}
\end{array}\right]
$$

is the result of the matrix product $M^{-1} \tau$.

From Equation (40), the transfer function which relates the yaw speed $\psi^{\prime}$ to the angle $\delta$ is obtained as

$$
G(s)=\frac{\psi^{\prime}}{\delta}(s)=\frac{b_{1} s+b_{2}}{\left(s^{2}+a_{1} s+a_{2}\right)}=\frac{K\left(1+s T_{3}\right)}{\left(1+s T_{1}\right)\left(1+s T_{2}\right)}
$$

Likewise, the transfer function which relates the transversal speed $v$ to the angle $\delta$ is given by

$$
H(s)=\frac{v}{\delta}(s)=\frac{c_{1} s+c_{2}}{\left(s^{2}+a_{1} s+a_{2}\right)}=\frac{K_{v}\left(1+s T_{v}\right)}{\left(1+s T_{1}\right)\left(1+s T_{2}\right)}
$$

where

$$
\begin{aligned}
& a_{1}=-a_{11}-a_{22} \\
& a_{2}=a_{11} a_{22}-a_{12} a_{21} \\
& b_{1}=b_{21} \\
& b_{2}=a_{21} b_{11}-a_{11} b_{21} \\
& c_{1}=b_{11} \\
& c_{2}=a_{12} b_{21}-a_{22} b_{11}
\end{aligned}
$$

$K, K_{v} T$ y $T_{v}$ are the gains and time constants of each transfer function.

Equation (43) is known as the Nomoto second-order model $[8,9,24,25,26,28,29]$ :

It is possible to transform Equation (43) into the time domain as

$$
T_{1} T_{2} \psi^{\prime \prime \prime}+\left(T_{1}+T_{2}\right) \psi^{\prime \prime}+\psi^{\prime}=K\left(\delta+T_{3} \delta^{\prime}\right)
$$

Noting again that $[25,26] \psi^{\prime}=r$, then

$$
T_{1} T_{2} r^{\prime \prime}+\left(T_{1}+T_{2}\right) r^{\prime}+r=K\left(\delta+T_{3} \delta^{\prime}\right)
$$


where

$$
\begin{aligned}
T_{1} T_{2} & =\frac{\operatorname{det}(M)}{\operatorname{det}(N)} \\
T_{1}+T_{2} & =\frac{\left(n_{11} m_{22}+n_{22} m_{11}-n_{12} m_{21}-n_{21} m_{12}\right)}{\operatorname{det}(N)}
\end{aligned}
$$

$$
\begin{aligned}
& K=\frac{n_{21} b_{1}-n_{11} b_{2}}{\operatorname{det}(N)} \\
& K T_{3}=\frac{\left(m_{21} b_{1}-m_{11} b_{2}\right)}{\operatorname{det}(N)} \\
& b_{1}=\frac{\left(I_{z z}-N_{r^{\prime}}\right) Y_{\delta}-\left(m x_{G}-Y_{r^{\prime}}\right) N_{\delta}}{\operatorname{det}(M)} \\
& b_{2}=\frac{\left(m-Y_{v^{\prime}}\right) N_{\delta}-\left(m x_{G}-N_{v^{\prime}}\right) Y_{\delta}}{\operatorname{det}(M)}
\end{aligned}
$$

$m_{i j}$ and $n_{i j}, i=1,2$ and $j=1,2$ are the elements of the matrices $M$ and $N$, respectively, which were defined in Equations (25) and (26).

For this case, $K=0.02012, T_{1}=1.233 \mathrm{~s}, T_{2}=8 \mathrm{~s}$, and $T_{3}=7.977 \mathrm{~s}$. Hence:

$$
G(s)=\frac{\psi^{\prime}}{\delta}(s)=\frac{0.1605 s+0.02012}{9.797 s^{2}+9.233 s+1}
$$

For the transversal speed: $K_{v}=0.06181$ and $T_{v}=$ 7.757 s. Hence:

$H(s)=\frac{v}{\delta}(s)=\frac{0.4795 s+0.06181}{9.7969 s^{2}+9.233 s+1}$
All these values were calculated using an algorithm developed in Matlab [30].

The behavior of the dynamic model under different operating conditions was obtained through computer simulations using Matlab [30]. The results are shown and explained in Section 8.

\section{Thruster model}

The thrusters are modeled as direct current motors; therefore, the transfer function [31] that models this type of system is

$$
\frac{\omega}{V}(s)=\frac{K_{t}}{\left(L_{a} s+R_{a}\right)\left(J_{m} s+b\right)+K_{t} K_{V}}
$$

Where $\omega$ is the angular speed of the propellers in $\mathrm{rad} / \mathrm{s}, V$ is the voltage applied to the thrusters in $V, K_{t}$ is the motor torque constant in $N-m / A, R_{a}$ is the armature resistance in $\Omega, L_{a}$ is the inductance of the motor armature in $H, J_{m}$ is the inertia moment of the rotor in $k g-m^{2}, b$ is the viscous friction coefficient in $N$ $\mathrm{m} / \mathrm{rad} / \mathrm{s}$, and $K_{V}$ is the speed constant in $V / \mathrm{rad} / \mathrm{s}$.

The calculated values of these constants are $K_{t}=K_{V}$ $=0.0382 \mathrm{~N}-\mathrm{m} / \mathrm{A}, L_{a}=0.3032 \mathrm{H}, R_{a}=5.42 \Omega, b=$ $2.69 \times 10^{-4} \mathrm{~N}-\mathrm{ms} / \mathrm{rad}, J_{m}=2.37 \times 10^{-4} \mathrm{~kg}-\mathrm{m}^{2}$. Using these values, the transfer function of the thruster is

$$
\frac{\omega}{V}(s)=\frac{0.0382}{7.186 \times 10^{-5} s^{2}+0.00366 s+0.002902}
$$

However, in this transfer function there is a degree of uncertainty due mainly to the fact that certain parameters of the thrusters are not provided by the manufacturer and therefore they are unknown. Under these circumstances, the error is of about $49.8 \%$ (see Table 1). To correct this situation, the transfer function is scaled by a factor $F_{c}$, called correction factor (Table 1 shows how this value was obtained). 
Design of a Teleoperated Aquatic Vehicle for the Gauging of Water Bodies, C.E. Díaz-Gutiérrez et al. / 394-418

\begin{tabular}{|l|l|l|l|l|l|l|l|}
\hline Voltage & $\omega_{m}$ & $\omega_{m}$ & $\omega_{s}$ & $\omega_{m} /{ }_{s}$ & Uncorrected error & ${ }_{s c}$ & $\begin{array}{l}\text { Error } \\
\text { corrected }\end{array}$ \\
\hline $\mathrm{V}$ & $r p m$ & $r a d / s$ & $r a d / s$ & Dimensionless & Percentage & rad/s & percentage \\
\hline 1.6 & 427 & 44.7153 & 21.06 & 2.1232353 & 52.9020641 & 42.86339947 & 4.141612614 \\
\hline 5.01 & 1174 & 122.941 & 65.95 & 1.864154663 & 31.7685688 & 134.227977 & 9.180807838 \\
\hline 7.63 & 1805 & 189.019 & 100.4 & 1.88266094 & 46.883691 & 204.3440316 & 8.10757693 \\
\hline 9.3 & 2329 & 243.892 & 122.4 & 1.99258423 & 49.8139158 & 249.1206123 & 2.143693089 \\
\hline 10.1 & 2600 & 272.271 & 132.9 & 2.04869348 & 51.1884032 & 270.491253 & 0.653800029 \\
\hline 10.45 & 2791 & 292.273 & 137.6 & 2.12407585 & 52.9207019 & 280.0571589 & 4.17954598 \\
\hline 10.94 & 2800 & 293.215 & 144 & 2.03621746 & 50.8893318 & 293.0830733 & 0.045100311 \\
\hline 11.23 & 2925 & 306.305 & 147.8 & 2.07243088 & 51.747486 & 300.8172099 & 1.791700652 \\
\hline 11.83 & 2980 & 312.065 & 155.7 & 2.0042702 & 50.1065276 & 316.896073 & 1.548140513 \\
\hline 11.66 & 3007.5 & 314.945 & 153.2 & 2.05577457 & 51.3565341 & 311.8078252 & 0.995996656 \\
\hline 11.83 & 3065 & 320.966 & 155.7 & 2.06143898 & 51.4901965 & 316.896073 & 1.26803954 \\
\hline 11.85 & 3076.5 & 322.17 & 156 & 2.0651944 & 51.5784083 & 317.5066627 & 1.447577103 \\
\hline 11.95 & 3108 & 325.469 & 157.3 & 2.06909726 & 51.6697441 & 320.1525516 & 1.633472725 \\
\hline 12.01 & 3112.5 & 325.94 & 158.1 & 2.06160808 & 51.4941754 & 321.7807909 & 1.276137907 \\
\hline 12.08 & 3140 & 328.82 & 159 & 2.06805051 & 51.6452816 & 323.6125601 & 1.583684243 \\
\hline & & & & 30.5294868 & 747.4550302 & & 39.99688613 \\
\hline & & Average & Fc=2.0353 & 49.8 & & 2.666 \\
\hline
\end{tabular}

Table 1. Obtaining the correction factor.

The introduction of this factor is justified in Section 8 (Results). With this correction factor, the error in the calculation of the original function is greatly reduced. Using a correction factor $F_{c}=2.0353$, the new transfer function is

$$
\frac{\omega}{V}(s)=\frac{0.07774846}{7.186 \times 10^{-5} s^{2}+0.00366 s+0.002902}
$$

For this case, the error is now only $2.6 \%$.

In the above table:

$\omega_{m}$, is the angular velocity measured using a tachometer.

$\omega_{s}$, is the angular velocity obtained through the transfer function of the thruster (Equation 62).
Uncorrected error: error obtained by expressing

$$
\% E=\left|\frac{\omega_{m}-\omega_{s}}{\omega_{m}}\right|(100)
$$

$\omega_{s c}$ is the angular speed corrected when this is multiplied by the correction factor; i.e.:

$$
\omega_{s c}=\omega_{s} F_{C} \text {. }
$$

Corrected error: is the error obtained through the equation

$$
\% E=\left|\frac{\omega_{m}-\omega_{s c}}{\omega_{m}}\right|(100)
$$

Difference: is given by $D=\left|\omega_{m}-\omega_{s c}\right|$ $\omega_{m} / \omega_{s}$, is the ratio $\omega_{m} \mathrm{y} \omega_{s}$. 
For each thruster, the resulting value of this function must be multiplied by the efficiency of the propellers $\eta_{0}$. The resulting transfer function is

$$
\frac{\omega}{V}(s)=\frac{0.03433372}{7.186 \times 10^{-5} s^{2}+0.00366 s+0.002902}
$$

\section{The PWM function}

The aim of the PWM (pulse width modulation) function is to establish the required $P W M$ and voltage to be applied to the thrusters to obtain different angular speeds. The relation between PWM and voltage was obtained experimentally in the laboratory (see Section 8). In the experiment, a linear relationship between the PWM and voltage was expected, however under certain type of switching of power devices, these can present a different behavior [32]. This is the case for the speed controllers used for control motors in SA-1 robot. According to the data, this relation can be approximated by the following fifth degree polynomial:

$$
\begin{aligned}
& V(P W M)=1.5714(P W M)^{5}-73.5(P W M)^{4}+1374.3 \\
& (P W M)^{3}-12840(P W M)^{2}+59950(P W M)-111888
\end{aligned}
$$

The correlation factor is 0.9974 , indicative of a good approximation. Hence, the operating range in which the simulations are performed is

$$
7.494 m s \leq P W M \leq 10.343 m s
$$

\section{Driving of the SA-1}

\subsection{Rudder Machine}

The rudder machine is in charge of turning a ship according to an order sent by the user. By rudder we should understood all devices employed to direct the flow and cause a turning effect or thrust. In this paper, the rudder has been represented by the symbol $\delta$. In the special case of the SA-1, the rudder is the device used for the maneuver to cause different velocities in their thrusters, in order to produce the gyro of the vehicle. In particular, the simulations were performed using a Microsoft Sidewinder wheel [34] shown in Figure 11.

\subsection{Direction dial}

For the simulation, the rudder machine has a direction dial, shown in Figure 10. The purpose of this dial is to represent graphically the angle that is making the robot turn. The rudder operates in the following range: $-30^{\circ} \leq \delta \leq 30^{\circ}$.

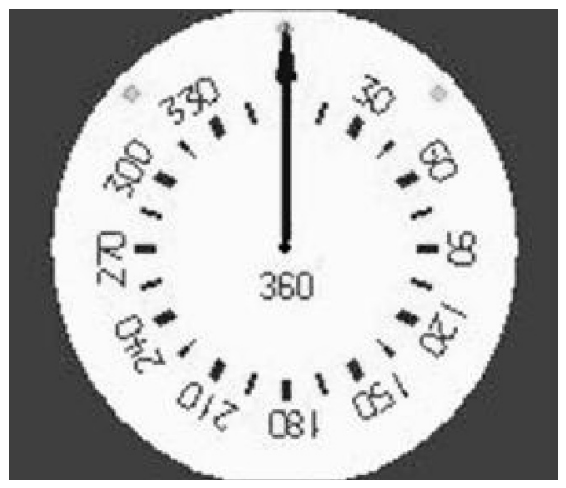

Figure 10. Direction dial used in the SA-1.

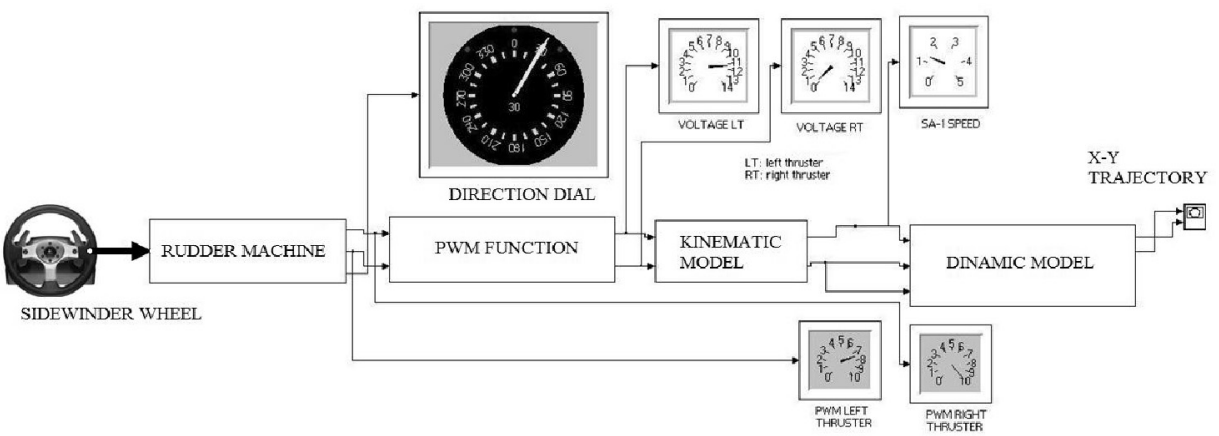

Figure 11. Simulink diagram showing all the modules that compose the SA-1. 
Figure 11 shows a Simulink diagram of all models developed in this paper.

In the next section the results obtained are presented.

\section{Simulation results}

\section{1. Propulsion system}

According to Equation (5), the graph obtained of the triad of equations that governs the behavior of the thrusters' propellers is shown in Figure 12.

The graph shows that for each revolution there exists a displacement of the robot of $0.10 \mathrm{~m} \mathrm{(100}$ $\mathrm{mm}$ ). Therefore, the pitch $P$ is equal to $0.1 \mathrm{~m}$.

\section{2. Kinematic model}

For a revolution of the propellers, the SA- 1 moves 0.1 $\mathrm{m}(10 \mathrm{~cm})$, according to the pitch value calculated. Figure 13 shows the result given by Equation (14).
In the next simulation test, the angular displacement generated by the two thrusters is again one revolution but in the opposite direction. Once again, the vehicle moves $0.1 \mathrm{~m}(10 \mathrm{~cm})$, but in reverse (Figure 14).

In Figure 15, the displacement of the SA-1 is shown when the ramp is applied to the right thruster. As expected, the turn is now clockwise.

In Figure 16, the displacement of the SA-1 is shown when the ramp is applied to the left thruster. As expected, the turn is now clockwise.

The value of the ramp applied to the left thruster is different to the value applied to the right thruster. For the purposes sought in this article, the kinematic model operates properly and is verifiable. Some authors [33] recommend to consider the torque in function of the relative speed between the water and the robot. However, only intended to demonstrate that the pitch may be used as an important parameter in the determination of a single kinematic model of unmanned surface vehicles.

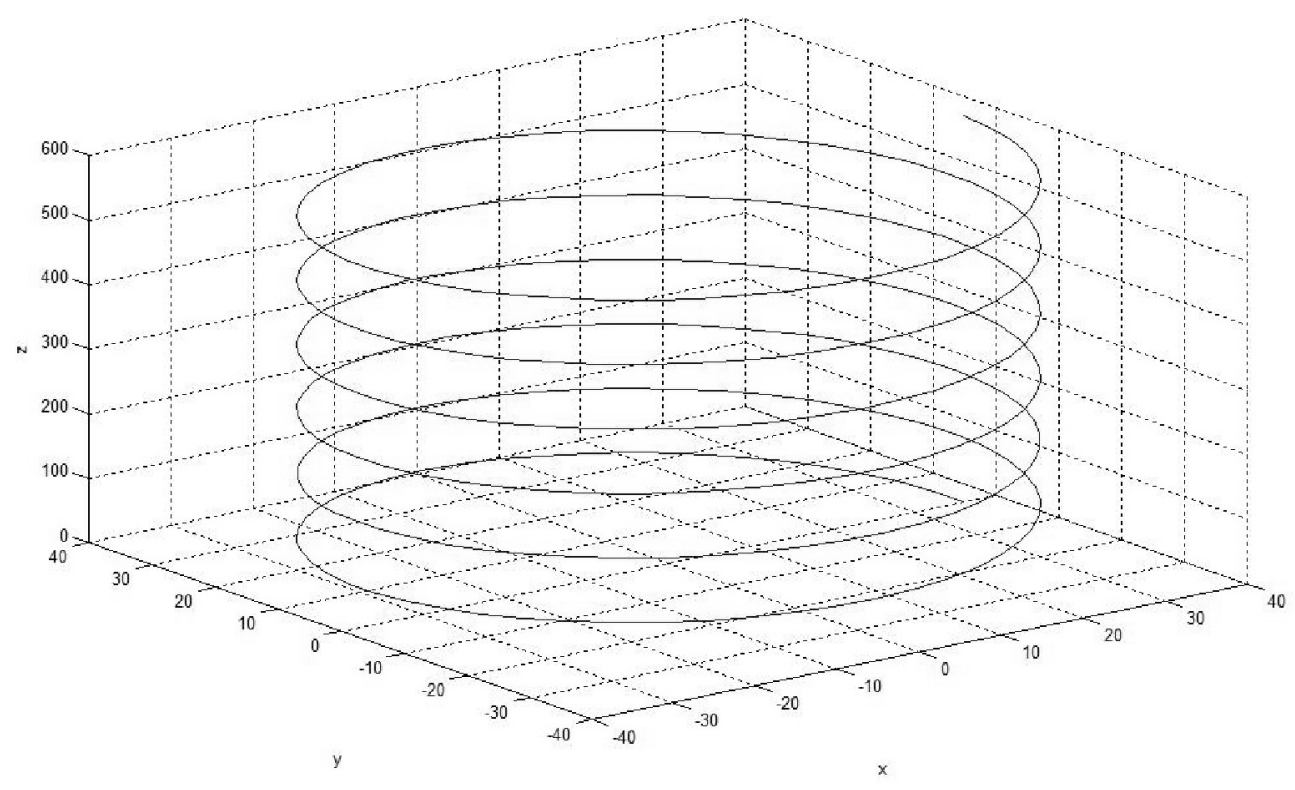

Figure 12. Curve generated by the movement of the propellers. 


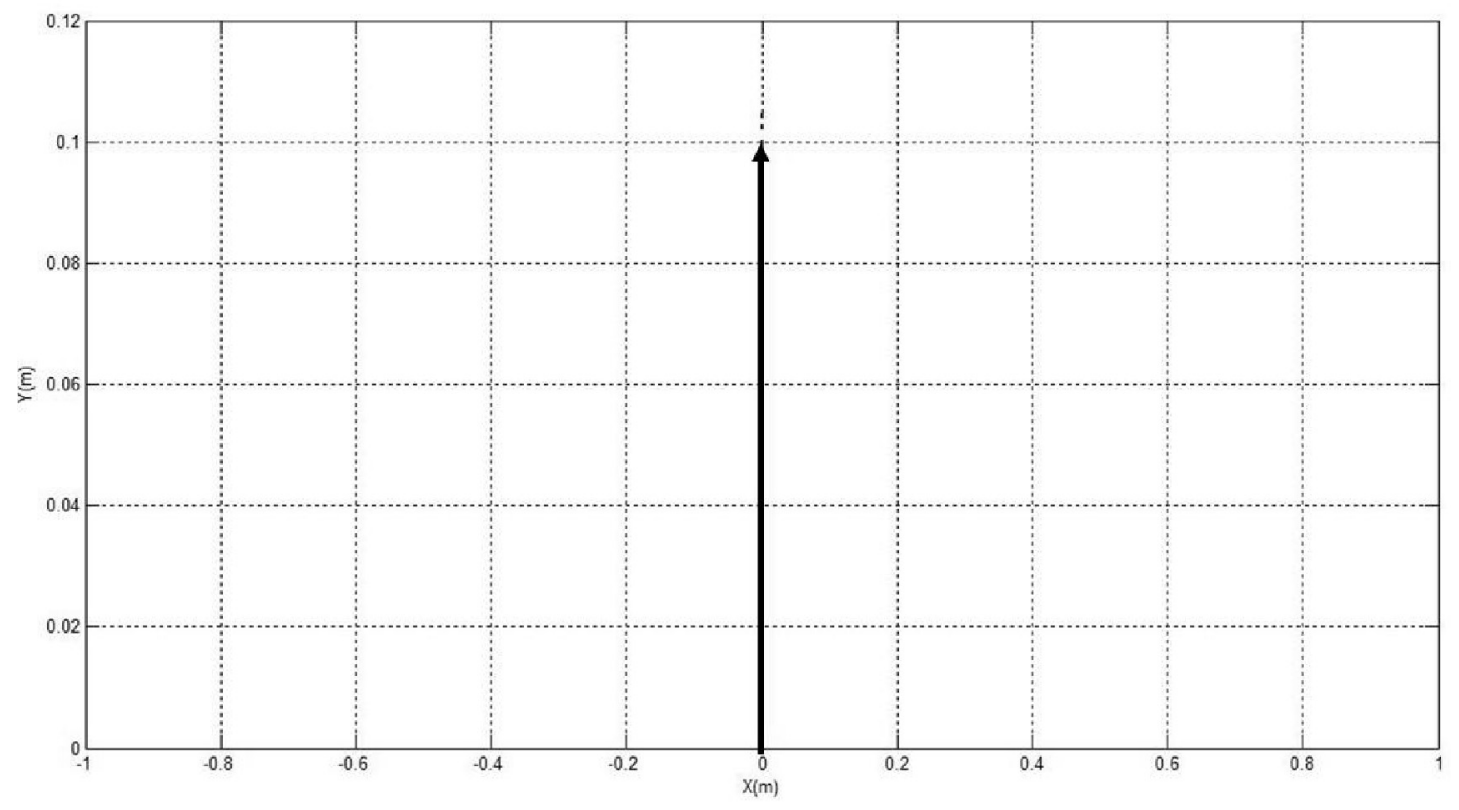

Figure 13. Displacement of the SA-1 when the propellers turn one revolution.

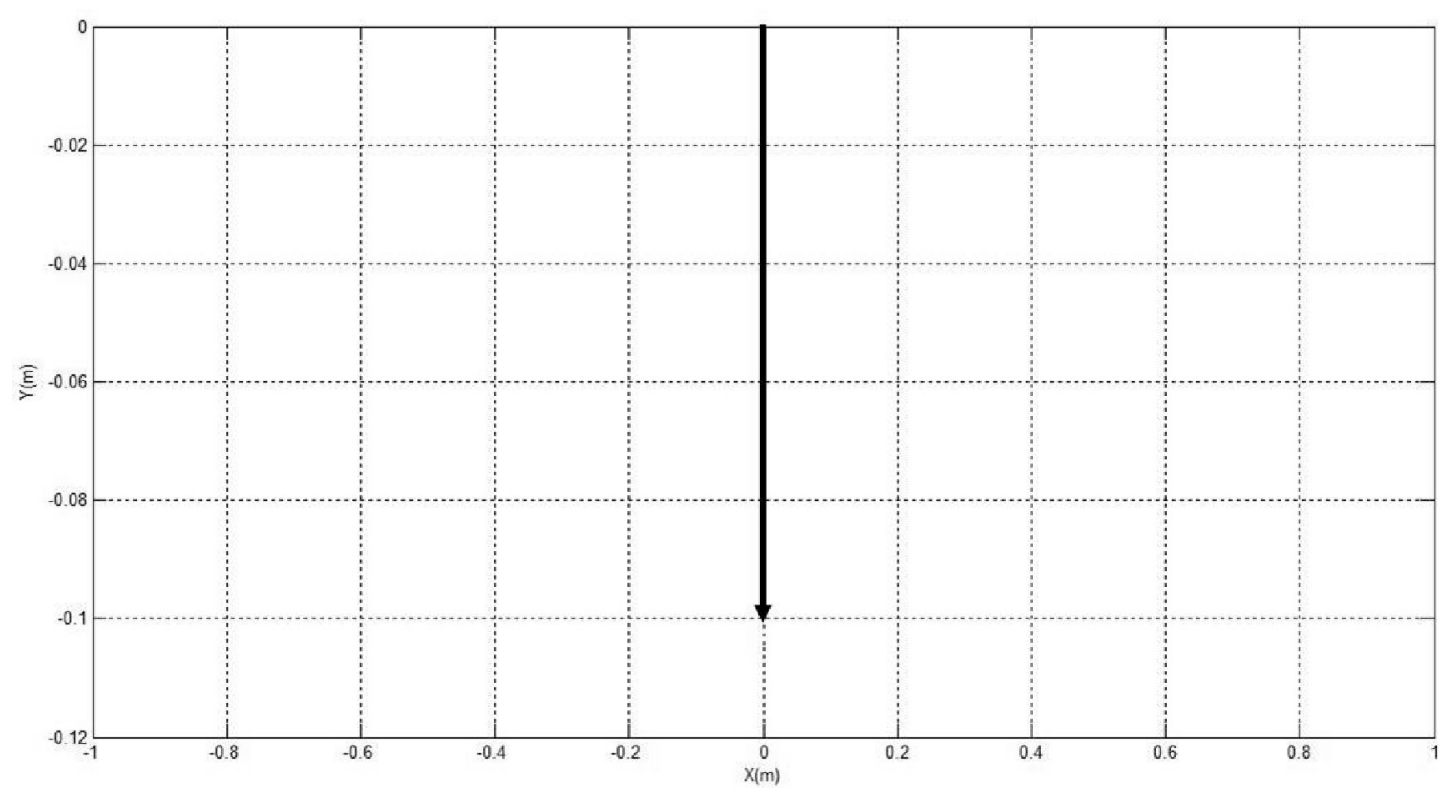

Figure 14. Displacement of the SA-1 when the propellers produce a turn of one revolution in the opposite direction. 


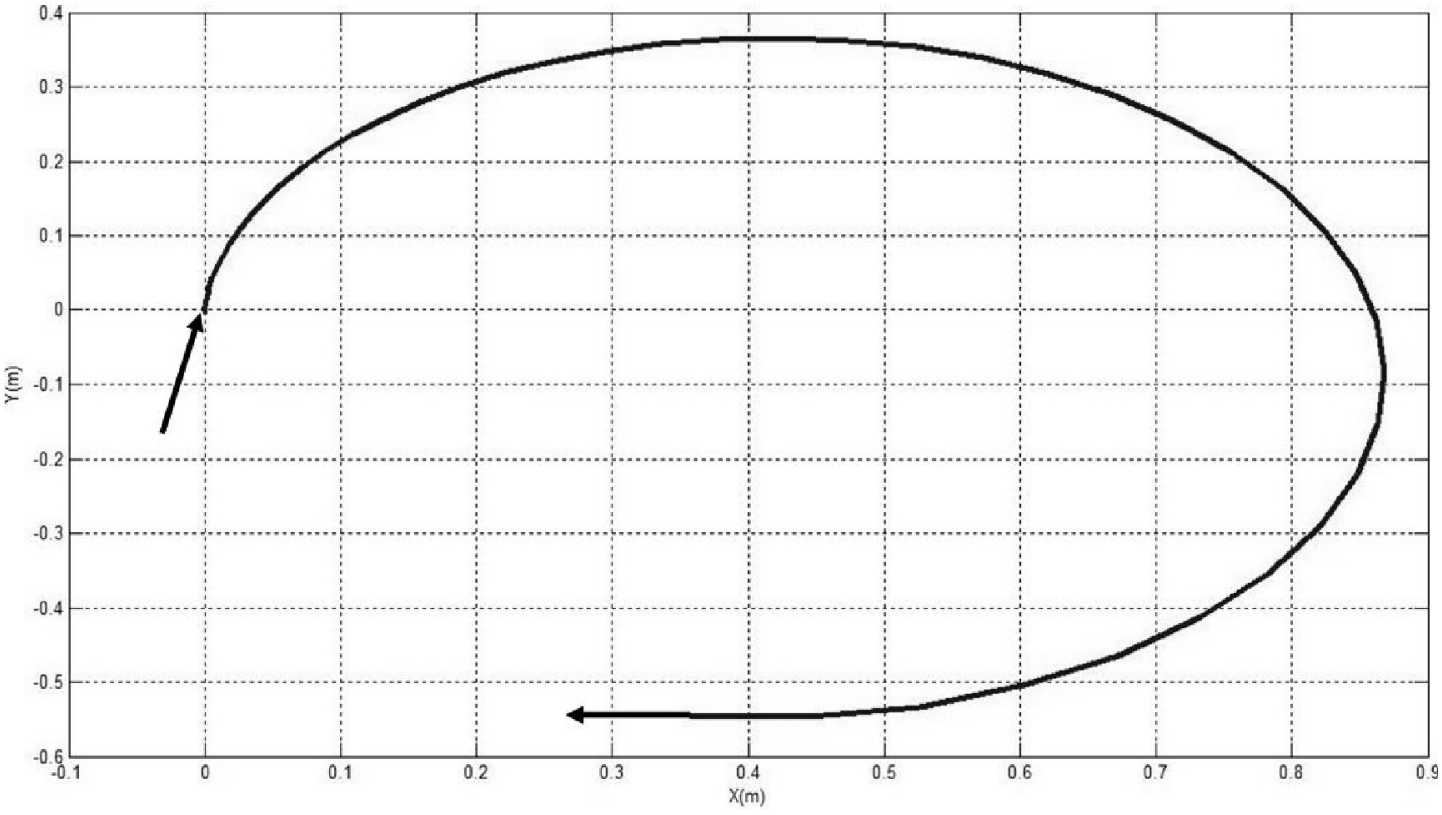

Figure 15. Displacement of the SA-1 when a ramp is applied to the right thruster.

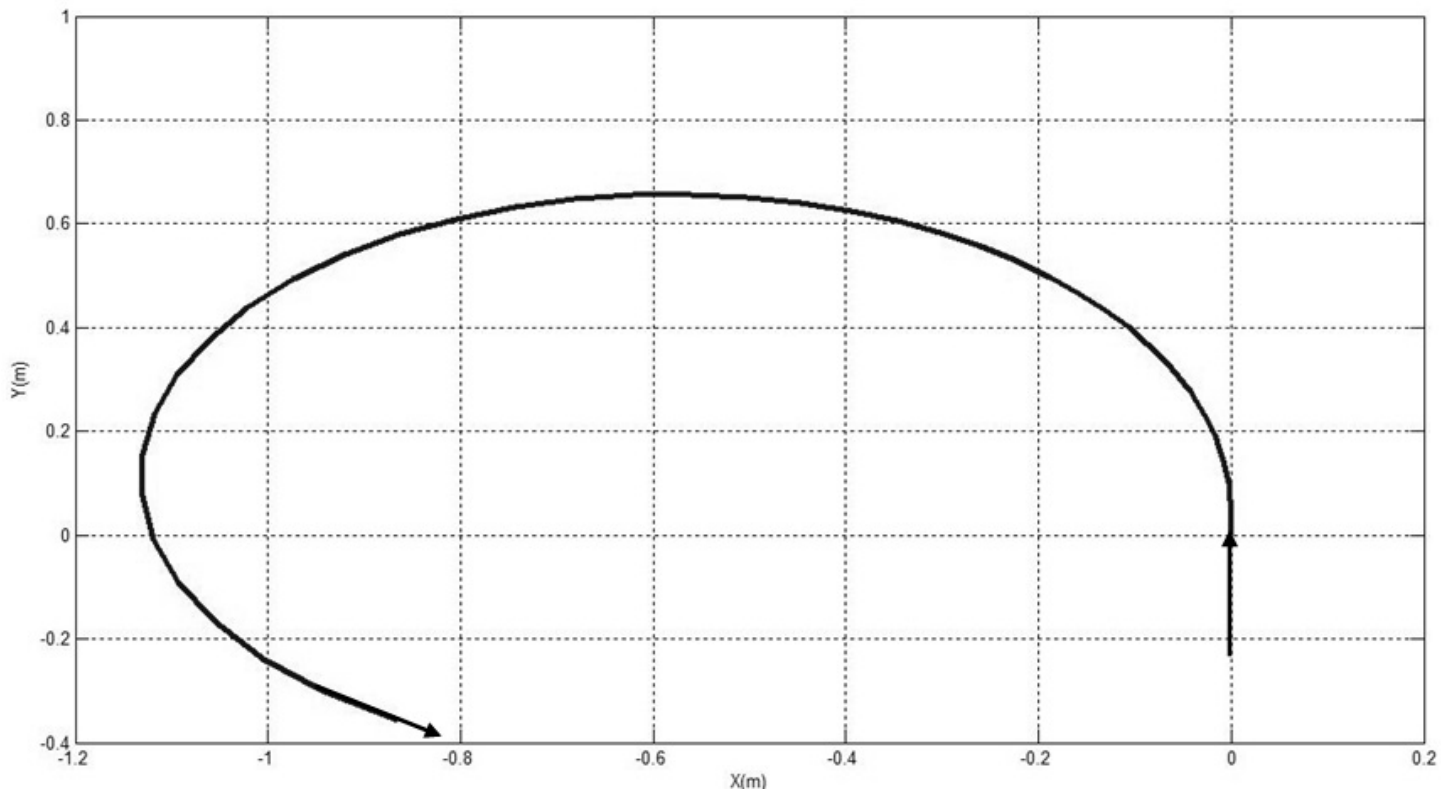

Figure 16. Displacement of the SA-1 when a ramp is applied to the left thruster. 


\subsection{Dynamic model}

It is important to note that the behavior of the dynamic model found using the procedure described in this paper is similar to that developed by Menezes for the aquatic platform Roboduck-ll . The Menezes' vehicle is used for environmental monitoring tasks and has characteristics analogous to those of the SA1. However, Menezes used a different procedure for the modeling of the platform that the one used here. $\mathrm{He}$ determined the yaw-rate from the rate gyro sensors [6] and then used Matlab to establish the transfer function of the dynamic model. This transfer function is a Nomoto first-order model given by [6]:

$$
G_{M}(s)=\frac{0.022478}{2.1245 s+1}
$$

The model proposed in Equation (59) can bee see as a first-order model given by

$$
G_{D}(s)=\frac{0.02012}{1.256 s+1}
$$

Figure 17 shows a comparative graph (response to unit step input) between the model of Menezes and the model developed in this paper (Equations 69 and 70, respectively).

This comparison shows that the dynamic model obtained through the procedure here described is adequate for the purposes intended in this paper.

\subsection{Thruster model}

The measured (real), original (uncorrected), and corrected angular velocities, obtained for different voltages applied to the thrusters, are shown in Figure 18. This figure shows the approximation to the real speed using the correction factor $F_{c}$.

Figure 19 shows the response of the original and corrected thruster model to a step input.

Figure 20 shows the response of the angular speed to stepwise voltages of $5,812,16$ and $18 \mathrm{~V}$ of magnitude applied to the thrusters. To appreciate the closeness of the model response with respect to the real system response, let us consider, for instance, the steady state speed of $475.9 \mathrm{rad} / \mathrm{s}$, obtained for the step input of $18 \mathrm{~V}$, is $475.9 \mathrm{rad} / \mathrm{s}$, and compare it to the measured speed of $471.24 \mathrm{rad} / \mathrm{s}$ for the same voltage. The relative error is $0.99 \%$, approximately.

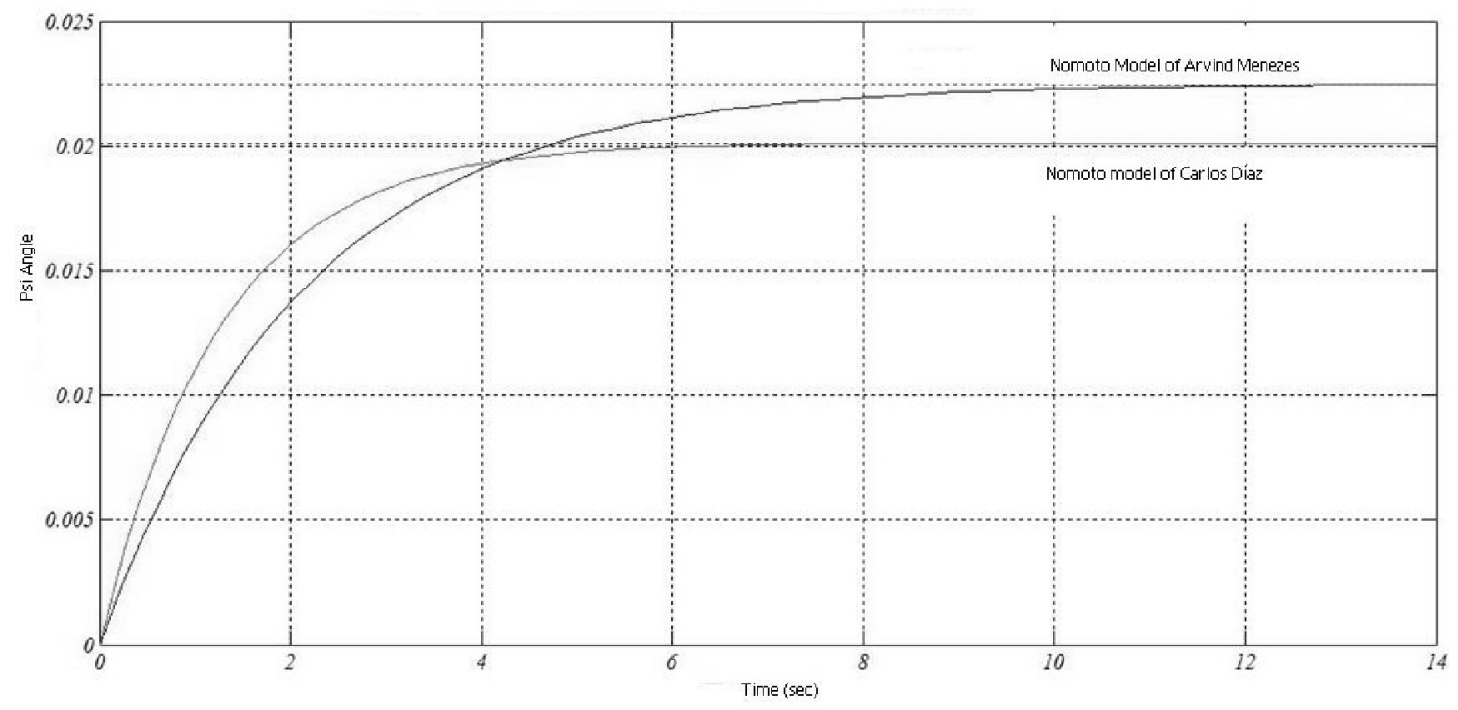

Figure 17. Nomoto model developed by Menezes for Roboduck-II and Nomoto Model developed by Díaz et al. (present work) for SA-1. 


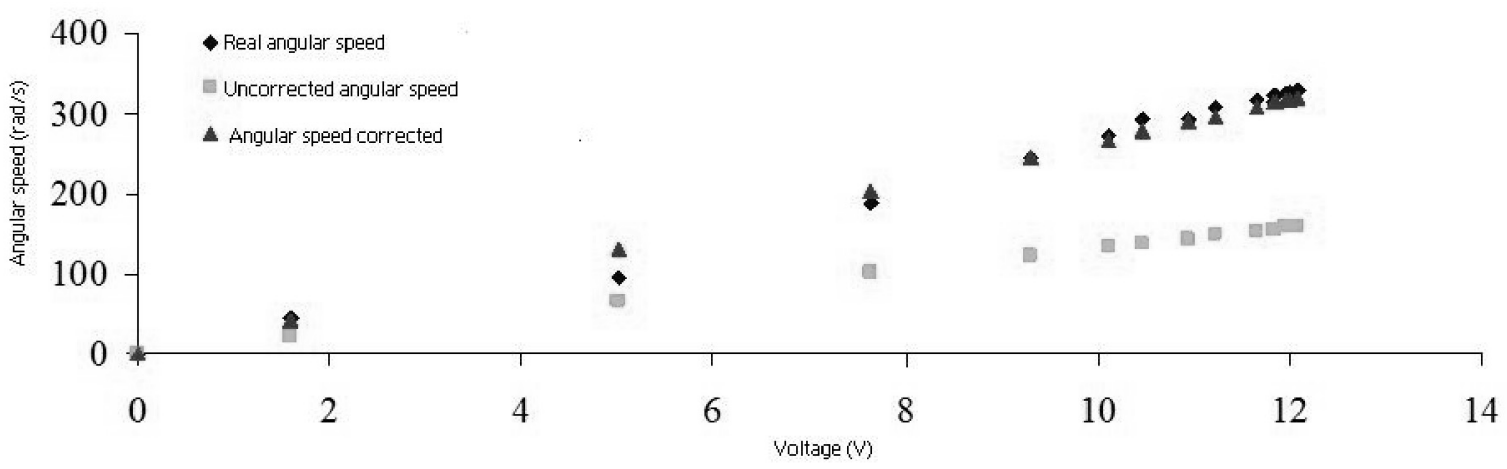

Figure 18. Measured (real), uncorrected, and corrected angular velocities obtained for different voltages applied to the thrusters.

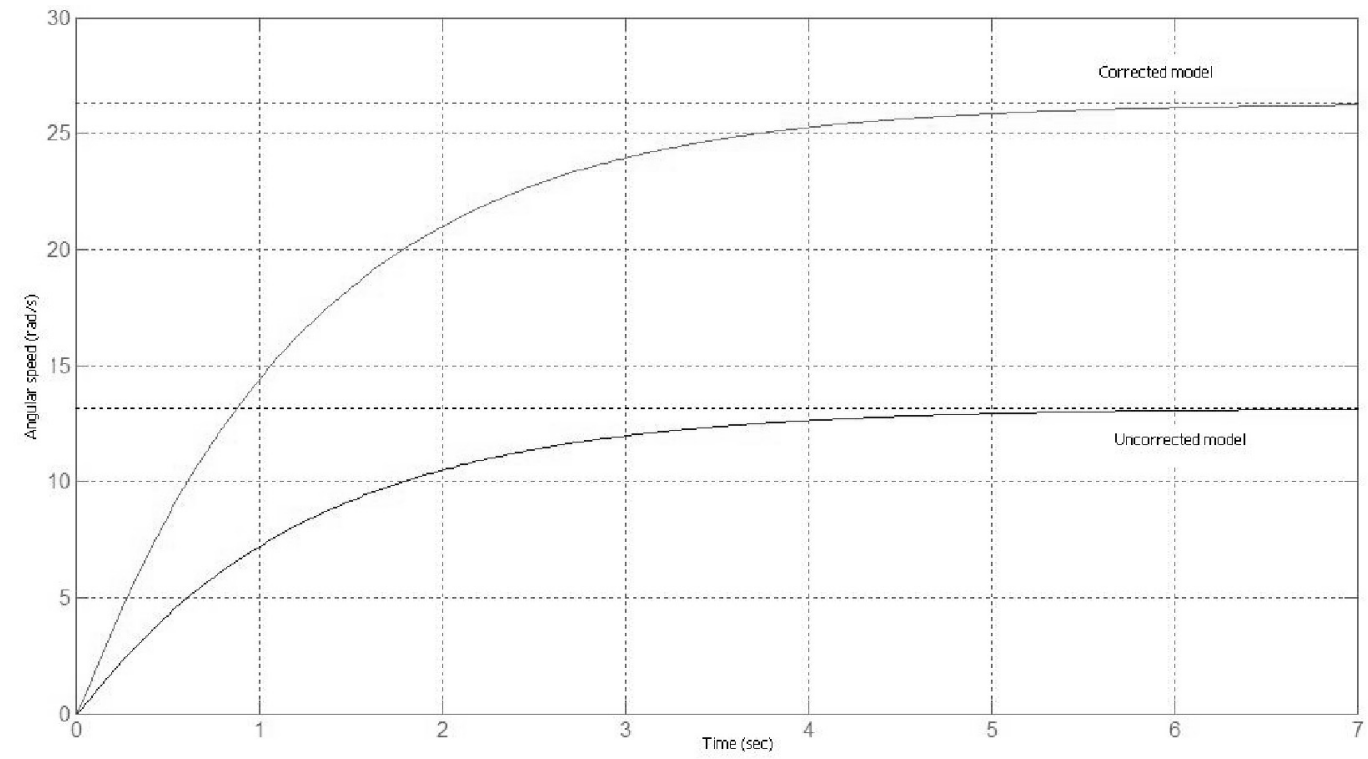

Figure 19. Step response of the original (uncorrected) and corrected thruster transfer functions. 


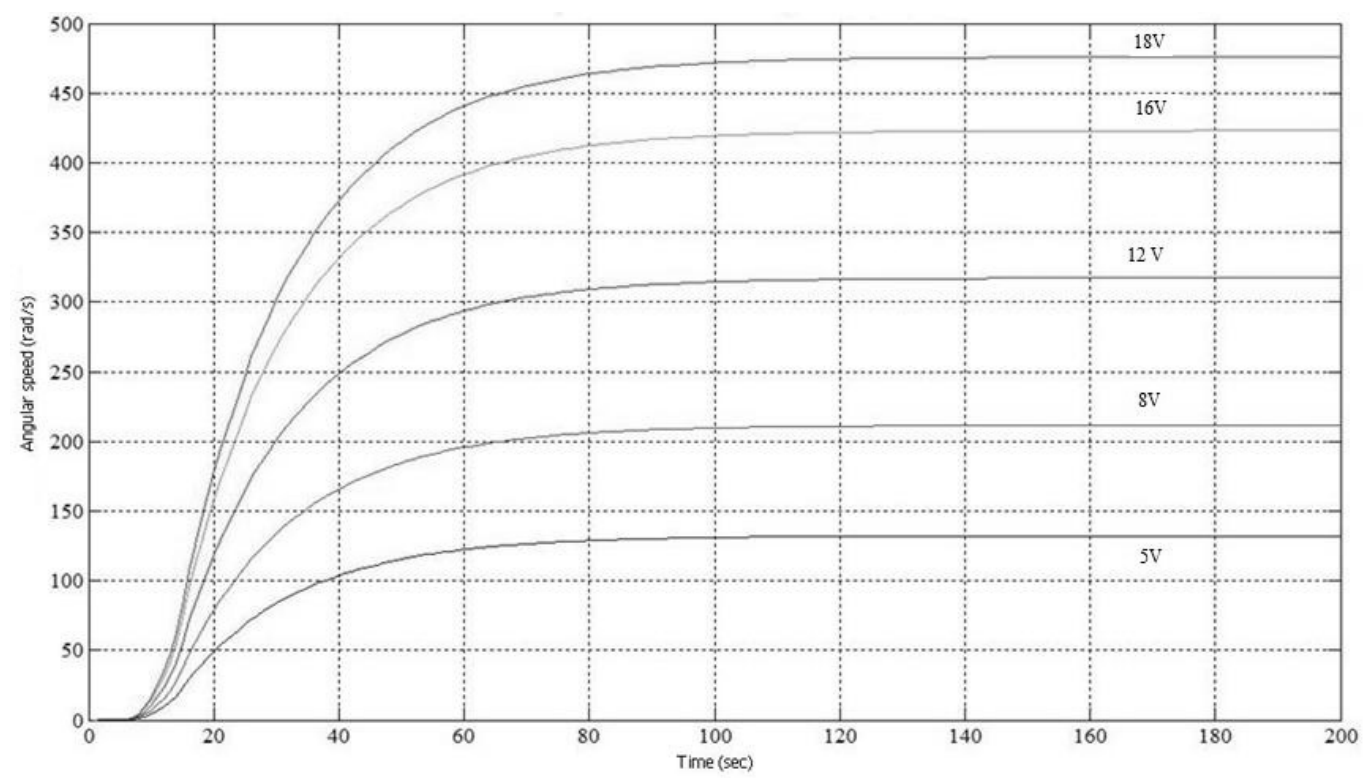

Figure 20. Corrected thruster transfer function response to different stepwise voltages.

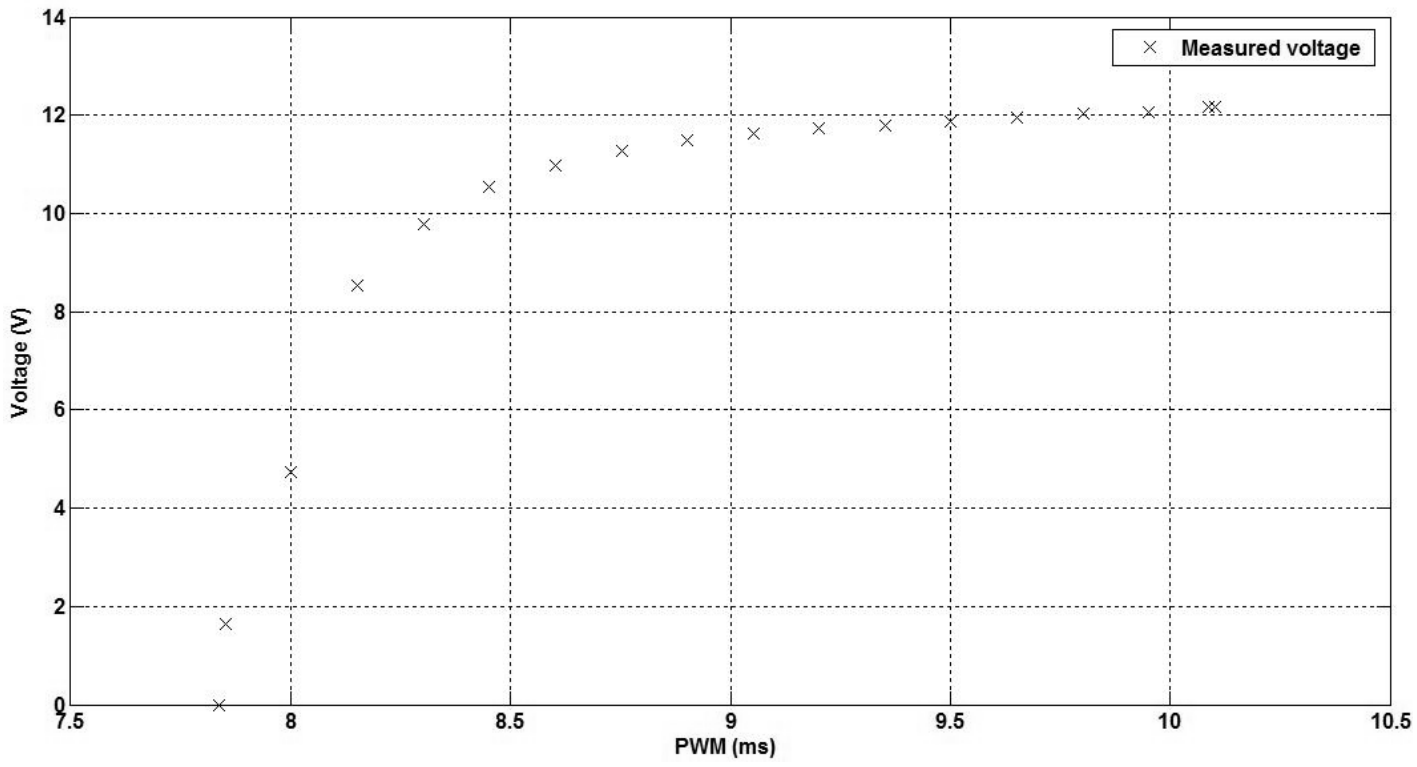

Figure 21. Measured voltage generated by the PWM command signal sent by the microcontroller. 


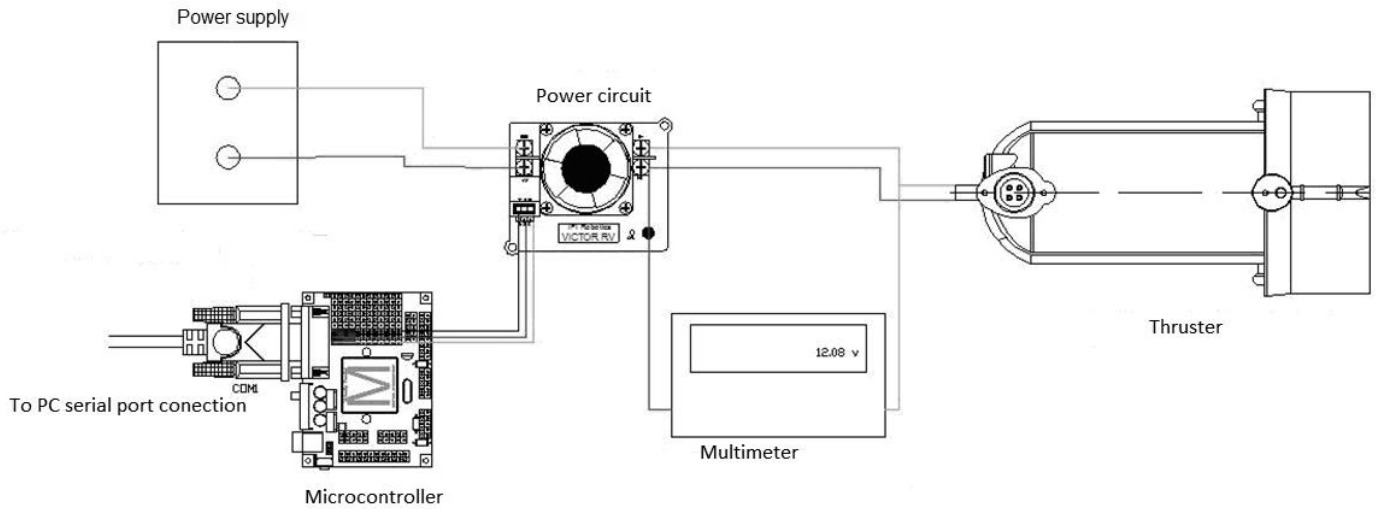

Figure 22. Circuit that generates the voltage according to the PWM command signal.

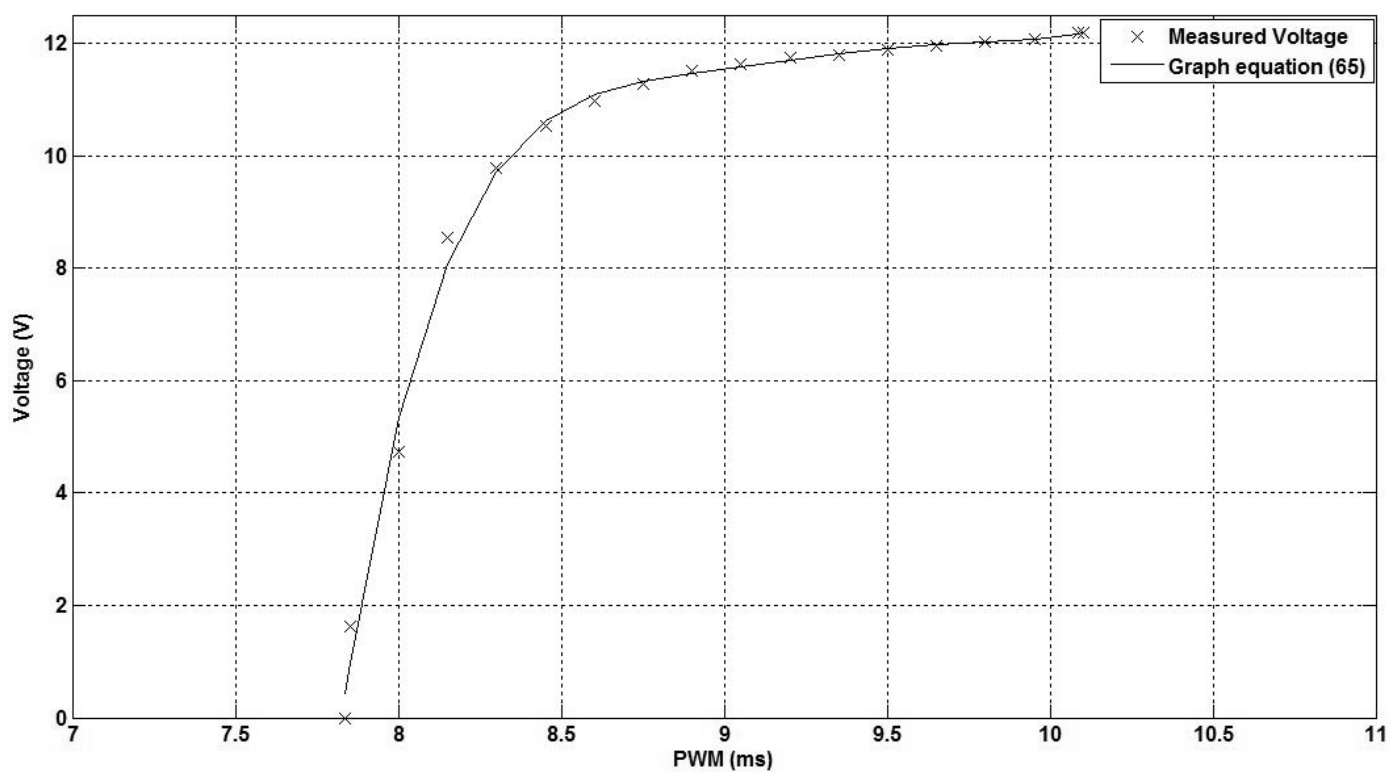

Figure 23. Graph obtained with equation 68. 


\subsection{PWM function}

Figure 21 shows the relationship between the PWM and the voltage measured at terminals of the power circuit (this circuit is described in Section 2.2).

The circuit that generates the voltage according to the PWM command signal is shown in Figure 22. A $12 \mathrm{~V}$ power supply is used in this circuit.

Figure 23 show the graph of Equation 68 and data measured experimentally.

\subsection{Rudder and Simulink model}

Figures 24 and 25 show some trajectories obtained with the rudder and the Simulink model. The command signals generate the desired trajectories, thus showing, through simulation, the fitness of the models created for the gauging system SA-1.

\section{a) Straight and left turn trajectory}

This trajectory was generated with the rudder in neutral position and with the same angular velocity in both thrusters. After a certain time, the rudder was turned 300 counter clockwise. The result of this operation is shown in Figure 24.

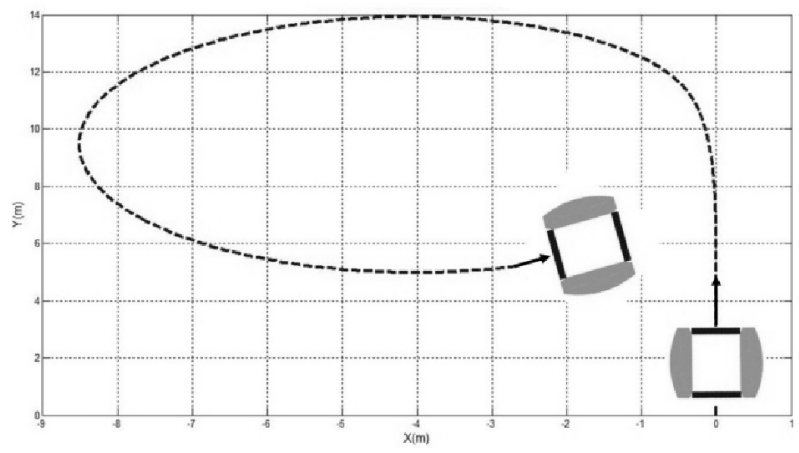

Figure 24. First trajectory generated.

b) Straight and right turn trajectory

This trajectory was generated with the rudder in neutral position and with the same angular velocity in both thrusters. After a certain time, the rudder was turned $30^{\circ}$ clockwise. The result of this operation is shown in Figure 25.

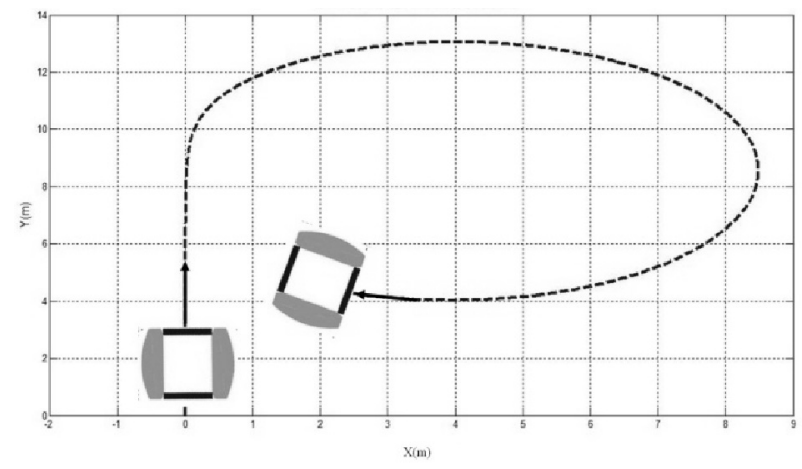

Figure 25. Second trajectory generated

Results obtained with the measurement system and other aspects related with the robot can be seen in the article Medición de caudales mediante la implementación de un vehículo acuático teleoperado [4].

\section{Conclusions}

The differential locomotion model proposed for the SA-1 works properly according to the design. With the calculation of the propeller pitch, it was possible to establish an analogy with differential earth vehicles and, thus, find out a suitable kinematic model based on this parameter.

The dynamic model of Nomoto works adequately within the model constraints (such as considerations made for the speed and thrust). The hydrodynamic coefficients were obtained using empirical equations which are, in turn, commonly used in large ships. The dynamic model was validated by comparing its step response to that obtained with the Menezes' model.

Despite existing many methods to determine some unknown characteristics of electric motors, here a new and rapid method was presented based in experimentation (such as the measure of voltage and angular speed with a multimeter and tachometer, respectively) and numerical methods to adjust the transfer function of the motors to more realistic conditions with a minimum of error and thus, obtaining a good model of these. Therefore, the thruster model obtained in this work is appropriate for the intended application of this platform. 
The PWM function shows a small error with respect to the experimental values; however, this value does not significantly affect the values of the output voltage that this function returns. Therefore, the PWM function developed is considered suitable for simulation purposes.

The simulations showed that the SA-1 can be positioned in any part of the body water, according to the user's requirements. Thus, the models and simulations developed in this article are appropriate and, in the future, will allow designing control systems that meet the needs of the aquatic platform and, hence, validating the models through the obtained experimental data.

\section{References}

[1] Gómez C. Manufacturer quotation. Geonica, Madrid, Spain, 2008.

[2] López Z. E. Manufacturer quotation. Aprotec Mexicana, S.A de C.V. Tijuana, Baja California, 2008.

[3] Gonzalez T. C., Cuellar R. D., Trujillo A. V., González L. System of automatization for measurement of volumen using windlass. Ingeniería Hoy. No. 25. Universidad del Cauca. Cauca, Colombia, 2006. pp. 43-46.

[4] Díaz G. C., Segovia J. A., Garduño G. M., Tejeda V. $\mathrm{S}$. Medición de caudales mediante la implementación de un vehículo acuático teleoperado. Accepted for publication in International Journal of Environmental Pollution. Centro de Ciencias Atmosféricas de la UNAM., No. 1., 2012.

[5] Velasco J. F.,. Rueda R. M. T, Lopez G. E., Moyano $P$. E. Mathematical model for govern control of ships. XXV Jornadas de Automática, 2004,.pp. 1-7.

[6] Menezes P. A. Navigation and guidance of an autonomous surface vehicle. Master of Science Thesis. University of Southern California, 2007.

[7] VanZwieten T. S.Dynamic simulation and control of an autonomous surface vehicle. Master of Science Thesis.. Atlanta University, 2003.

[8] C.Yaw Tzeng, J. Fen Chen Fundamental properties of linear ship steering dynamic models. Journal of Marine Science and Technology, 1999. pp. 79-88.

[9] J. V. Amerongen "Adaptive Steering of ships. A model reference approach to improved maneuvering and economical course keeping". PhD thesis. Delft University of Technology, (2005).

[10] Caccia M., Bono R., Bruzzone Gabrielle, Bruzzone Giorgio, Spirandelli E., Veruggio G., Stortini M., Capodaglio G. Sampling sea surface with SESAMO. An autonomous craft for the study of sea-air interactions. IEEE, Robotics and Automation Magazine, 2005. 10709932/05. pp. 2-10.

[11] Alves P., Oliveira R., Pascoal A., Rufino L., Silvestre C. Vehicle and mission control of the DELFIM. Autonomous Surface Craft. IEEE Mediterranean Conference on Control and Automation, 2006. 09786720-1-1. pp. 1-6.

[12] Steanley J. M., Singh A., Batalin M., Jordan B., Kaiser W. NIMS-AQ: A novel system for autonomous sensing of aquatics environments. IEEE International Conference on Robotics and Automation, 2008. ISNN 1050- 4729. pp. 621- 628.

[13] Ferreira H., Martins A., Dias A., Almeida C., Almeida J. M., Silva E. P. Roaz autonomous surface Vehicle design and implementation. IEEE Robotics. ISBN 1424406021, 2006.

[14] PCM-9375. Users Manual. 2nd Edition. 2007.

[15] Velasco F. J., Revestido E., Moyano E., López E., Remote Laboratory for marine vehicles experimentation. Journal of Computer Applied Engineer Education, 2010. pp. 1-13.

[16] Tupper E., Introduction to naval architecture. London, England ,2002.

[17] Zill G. D., Calculus with analytical geometry, México, D.F,.1994.

[18] Seabotix. BTD 150 Data Sheet, 2005

[19] Ollero B. A., Robotics, manipulators and movile robot,México, D.F., 2007.

[20] Domínguez D.VRML and Simulink interface for the development of 3-D simulator for mobile robots. 31 World Academy of Science, Engineering and Technology. (2007). 12-16 pp.

[21] Albagul A., Wahyudi. Dynamic Modelling and adaptive traction control for mobile robots. International Journal of advanced Robotics Systems (2004). 149-154.

[22] Worral K. J., McGookin W. E. A mathematical model of a lego differential drive robot. USTRATH. 2002. pp. 1-6. 
[23] Asencio J. R., Montano L. A kinematic and dynamic model-based motion controller for mobile robots. 15th Triennial World Congress, 2002.

[24] Ayza J., López J., Quevedo J. Modelización de la dinámica de un buque. Qüestió. (1980). 137-146.

[25] Velasco J. F., Rueda R. M. T., Lopez G. E., Moyano $P$. E. Mathematical model for govern control of ships. XXV Jornadas de Automática, 2004. pp. 1-7.

[26] Fossen T. I. Guidance and control of ocean vehicles, London, England 1994.

[27] Comstock J. P., Principles of naval architecture (New York, USA 1967).

[28] Velasco J. F. Simulations of an autonomous in-scale fast-ferry model. International Journal of of systems applications, engineering a development. Issue 3 . Volume 2.

[29] Tomera M.. Nonlinear controller design of a ship autopilot. International journal of applied mathematics computer science. (2010). pp. 271-280.

[30] Mathworks , Mathlab. The language of technical computing". www. mathworks.com. 10/03/2011, 2011.

[31] Bañó. A. A. Analysis and design control of a position for a mobile robot with differential traction. Memoria. Universitat Rovira I Virgili. Escola Técnica Superior Enginyeria. Catalunya, España, 2003.

[32] Segovia A. Zapata R., Lepinay P., Control PWM: Algunas Consideraciones de Diseño, ELECTRO 2003, Chihuahua, Chih. ISSN 1405-2172, Octubre 2003, pp. 17-22.

[33] Chanop S. A.. Autonomous Underwater Robot: Visión and Control. Master of Endineering Thesis. The Australian National University, 2001.

[34] Microsoft, Sidewider wheel. www. Microsoft. com, 10/03/2011, 2011. 


\section{Authors' Biographies}

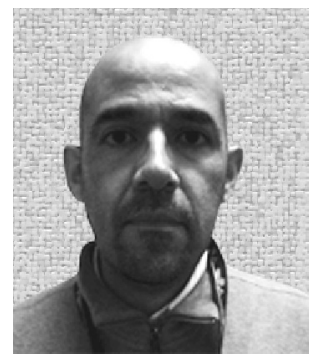

\section{Carlos E. DIAZ-GUTIÉRREZ}

Mr. Díaz-Gutiérrez performed his M. E. studies in manufacturing systems from 2003 to 2006 at Universidad Autónoma del Estado de México. Currently he is a Ph.D. student in electronic engineering science at Instituto Tecnológico de Toluca, Mexico and professor-researcher at Universidad Tecnológica del Valle de Toluca, Mexico. His interests include sensors, unmanned surface vehicles, exoskeletons and medical robotics.

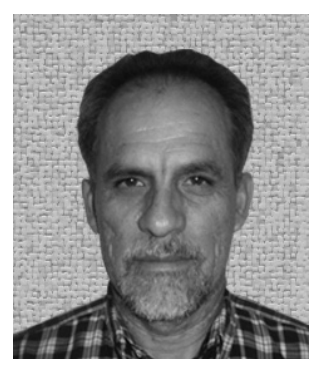

\section{Armando SEGOVIA-DE LOS RÍOS}

Dr. Segovia-de los Ríos received the M.S. degree from the Department of Electrical Engineering, Mexico in 1984, and the Ph.D. degree in computing sciences from Université de Technologie de Compiègne, France in 1993. Since 1995 he has been a researcher in mobile robotics and artificial vision at the National Institute for Nuclear Research, Mexico. He is a professorresearcher at the Electronic Research and Postgraduate Studies Department at Instituto Tecnológico de Toluca, Mexico. His interests include path planning, visual servo control, simultaneous localization and mapping, wireless networks and embedded control.

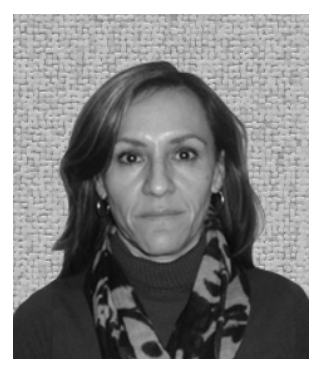

\section{Mayra GARDUÑO-GAFFARE}

Dr. Garduño-Gaffare pursued her M.S. studies in computing sciences from 1988 to 1990, and in 2005 she received the Ph.D degree, both, from the Computing Science Research and Postgraduate Studies Department from Instituto Tecnológico de Toluca. From 1991 to 1994, she pursued her doctoral studies at Université de Technologie de Compiègne, France. Currently, she is a professor-researcher at the Electronic Research and Postgraduate Studies Department at Instituto Tecnológico de Toluca, Mexico. Her interests include path planning, mobile robot localization, kalman filtering, and wireless networks. 


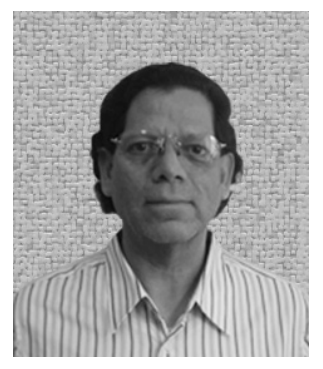

\section{Jorge S. BENÍTEZ-READ}

Dr. Benítez-Read received the B.Sc. degree in industrial engineering in electronics from Instituto de Tecnología de Chihuahua, Mexico, in 1979; and the M.Eng. and Ph.D. degrees in electrical engineering from the University of Toronto, Canada in 1985, and the University of New Mexico, USA in 1992, respectively. He spent a year, from 1980 to 1981, at Escuela de Ingenieros Industriales and Empresarios Agrupados nuclear engineering company, in Madrid, Spain, in a specialization program in nuclear technology. In 1981 he joined the National Nuclear Research Institute (ININ) of Mexico where he currently works in the area of control of nuclear systems. Since 1987, he lectures graduate courses in control and electronics at Instituto de Tecnología de Toluca, Mexico. 